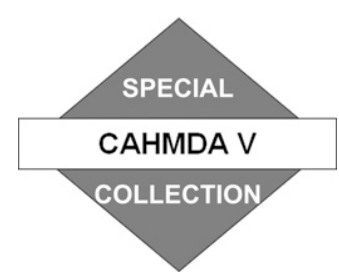

\title{
Assessment of Roughness Length Schemes Implemented within the Noah Land Surface Model for High-Altitude Regions
}

\author{
DONGHAI ZHENG \\ Faculty of Geo-Information Science and Earth Observation, and Faculty of Engineering Technology, University \\ of Twente, Enschede, Netherlands \\ ROGIER VAN DER VELDE AND ZHONGBO SU \\ Faculty of Geo-Information Science and Earth Observation, University of Twente, Enschede, Netherlands \\ MARTIJN J. BOOIJ AND ARJEN Y. HOEKSTRA \\ Faculty of Engineering Technology, University of Twente, Enschede, Netherlands \\ JUN WEN \\ Cold and Arid Regions Environmental and Engineering Research Institute, Chinese Academy of Sciences, Lanzhou, China
}

(Manuscript received 8 June 2013, in final form 11 October 2013)

\begin{abstract}
Current land surface models still have difficulties with producing reliable surface heat fluxes and skin temperature $\left(T_{\text {sfc }}\right)$ estimates for high-altitude regions, which may be addressed via adequate parameterization of the roughness lengths for momentum $\left(z_{0 \mathrm{~m}}\right)$ and heat $\left(z_{0 \mathrm{~h}}\right)$ transfer. In this study, the performance of various $z_{0 \mathrm{~h}}$ and $z_{0 \mathrm{~m}}$ schemes developed for the Noah land surface model is assessed for a high-altitude site $(3430 \mathrm{~m})$ on the northeastern part of the Tibetan Plateau. Based on the in situ surface heat fluxes and profile measurements of wind and temperature, monthly variations of $z_{0 \mathrm{~m}}$ and diurnal variations of $z_{0 \mathrm{~h}}$ are derived through application of the Monin-Obukhov similarity theory. These derived values together with the measured heat fluxes are utilized to assess the performance of those $z_{0 \mathrm{~m}}$ and $z_{0 \mathrm{~h}}$ schemes for different seasons. The analyses show that the $z_{0 \mathrm{~m}}$ dynamics are related to vegetation dynamics and soil water freeze-thaw state, which are reproduced satisfactorily with current $z_{0 \mathrm{~m}}$ schemes. Further, it is demonstrated that the heat flux simulations are very sensitive to the diurnal variations of $z_{0 \mathrm{~h}}$. The newly developed $z_{0 \mathrm{~h}}$ schemes all capture, at least over the sparse vegetated surfaces during the winter season, the observed diurnal variability much better than the original one. It should, however, be noted that for the dense vegetated surfaces during the spring and monsoon seasons, not all newly developed schemes perform consistently better than the original one. With the most promising schemes, the Noah simulated sensible heat flux, latent heat flux, $T_{\text {sfc }}$, and soil temperature improved for the monsoon season by about $29 \%, 79 \%, 75 \%$, and $81 \%$, respectively. In addition, the impact of $T_{\text {sfc }}$ calculation and energy balance closure associated with measurement uncertainties on the above findings are discussed, and the selection of the appropriate $z_{0 \mathrm{~h}}$ scheme for applications is addressed.
\end{abstract}

\section{Introduction}

High-altitude regions, such as the source region of the Yellow River (SRYR) in the northeastern part of the Tibetan Plateau, have seen recently a striking air and ground surface warming (Zhao et al. 2004; Wang et al.

Corresponding author address: Donghai Zheng, University of Twente, P.O. Box 217, 7500 AE Enschede, Netherlands.

E-mail: d.zheng@utwente.nl
2008; Qin et al. 2009; Yang et al. 2011a; Wu et al. 2012), accompanied with noticeable ecological and hydrological changes (Wang et al. 2003; Yang et al. 2007; Yang et al. 2011b; Zhou and Huang 2012). Heat flux exchanges at the land-atmosphere interface play an important role in controlling the atmospheric heating and ground warming. It is, therefore, vital to be able to simulate the surface heat fluxes transfer accurately for quantifying and predicting the impact of global warming on the ecologically fragile high-altitude regions, such as the SRYR. 
Models of the surface heat fluxes transfer between the land surface and atmosphere usually employ the bulk formulations based on the Monin-Obukhov similarity theory (MOST; Garratt 1994; Brutsaert 1998; Su et al. 2001). The MOST relates the sensible heat flux $(H)$ to the gradient of the ground surface temperature $\left(T_{\mathrm{sfc}}\right)$ and the temperature in the atmospheric surface layer. To accurately calculate $H$ by means of similarity theory, the roughness lengths for momentum $\left(z_{0 \mathrm{~m}}\right)$ and heat $\left(z_{0 \mathrm{~h}}\right)$ transfer must be determined (Su et al. 2001). Both parameters cannot be measured directly. Their values are ideally determined using the bulk transfer equations from wind and temperature profile measurements (Schaudt 1998; Sun 1999; Ma et al. 2002; Yang et al. 2003) and/or from single-level sonic anemometer measurements (Sun 1999; Martano 2000; Ma et al. 2008b). The lack of profile and sonic anemometer data in many regions, however, makes it difficult to determine both parameters on a global scale.

Many studies have been conducted to relate the momentum roughness length $z_{0 \mathrm{~m}}$ to simple geometric characteristics of the surface, such as canopy height (Brutsaert 1982), leaf area index (LAI; Su 2002), normalized difference vegetation index (NDVI; Bastiaanssen et al. 1998), land cover (Wiernga 1993) and green vegetation fraction (GVF; Zheng et al. 2012, hereafter Z12). Meanwhile, the thermal roughness length $z_{0 \mathrm{~h}}$ is usually converted from $z_{0 \mathrm{~m}}$ by the factor $k B^{-1}\left[k B^{-1}=\ln \left(z_{0 \mathrm{~m}} / z_{0 \mathrm{~h}}\right)\right]$. The parameterization of $k B^{-1}$ has stimulated numerous theoretical and experimental investigations over past decades. See, for example, Brutsaert (1982), Su et al. (2001), and Yang et al. (2008, hereafter Y08) for detailed reviews on $k B^{-1}$. Brutsaert (1982) showed that $k B^{-1}$ can be parameterized by a combination of roughness Reynolds number $\left(\operatorname{Re}_{*}\right)$ and vegetation parameters, such as LAI and canopy structure. Sun (1999) also found that $k B^{-1}$ may vary diurnally over homogeneous grassland, and these diurnal variations are not uniquely related to the $\mathrm{Re}_{*}$. It was further pointed out by Y08 that $k B^{-1}$ may be related to the type of flow and that the diurnal variations can be more realistically parameterized by a combination of friction velocity $\left(u_{*}\right)$ and friction temperature $\left(\theta_{*}\right)$.

Even stronger diurnal patterns in $k B^{-1}$ have been observed over the Tibetan Plateau. Since 1998, intensive field experiments and comprehensive observational networks have been and are being developed on the Tibetan Plateau (Koike 2004; Ma et al. 2008a; Xu et al. 2008), which have advanced our understanding on the diurnal $k B^{-1}$ behavior over this high-altitude alpine area (Ma et al. 2002, 2008b; Yang et al. 2003; Y08; Wang and Ma 2011). Even though these studies have resulted in numerous improvements in the parameterization of $k B^{-1}$, Chen et al. $(2010,2011)$ have recently shown that the current land surface models (LSMs; e.g., Noah LSM) still have difficulties with producing reliable daytime $H$ and $T_{\text {sfc }}$ simulations over arid and semiarid regions, such as the Tibetan Plateau. A successful modeling of the diurnal $k B^{-1}$ variations is the key for improving the simulations of $H$ and $T_{\mathrm{sfc}}$ as well as the overall model performance.

The potential of improving the daytime $H$ and $T_{\text {sfc }}$ simulations over arid regions through a revision of the $k B^{-1}$ scheme has previously been investigated by Zeng et al. (2012) for the Noah and Community Land Model (CLM). The performance of Noah's $k B^{-1}$ scheme was enhanced by only modifying the empirical coefficient of the original scheme by Zilitinkevich (1995). Similar modifications to the original $k B^{-1}$ scheme of Noah were proposed by Chen and Zhang (2009) and Z12. For instance, Chen and Zhang (2009) implemented Zilitinkevich's empirical coefficient $\left(C_{\mathrm{zil}}\right)$ as a function of the canopy height, whereas Z12 utilized the GVF for calculating $k B^{-1}$. An alternative way toward improving the $k B^{-1}$ calculation within Noah is the implementation of the scheme specific for $z_{0 \mathrm{~h}}$ by Y08 as reported by Chen et al. $(2010,2011)$.

The performance of these three newly developed $k B^{-1}$ schemes for the Noah LSM has so far not been evaluated for different seasons across the Tibetan Plateau. Only Chen et al. (2010) have investigated modeling results obtained with the $z_{0 \mathrm{~h}}$ scheme by Y08 for 2-month premonsoon episodes. In this investigation, we evaluate the performance of those $k B^{-1}$ schemes for a Tibetan Plateau site in different seasons. A long-term dataset collected at the Maqu station $\left(33.88^{\circ} \mathrm{N}, 102.15^{\circ} \mathrm{E}\right.$ at an altitude of about $\left.3430 \mathrm{~m}\right)$ from 20 May 2009 to 17 May 2010 is used for this analysis. The dataset includes eddy covariance (EC) measurements and profile measurements of wind, temperature, and humidity. The bulk MOST formulation is used in combination with these micrometeorological measurements to derive values for $z_{0 \mathrm{~m}}, z_{0 \mathrm{~h}}$, and $k B^{-1}$. Subsequently, these $z_{0 \mathrm{~m}}, z_{0 \mathrm{~h}}$, and $k B^{-1}$ values are utilized together with the $H$ measurements to assess the performance of the various $z_{0 \mathrm{~m}}$ and $z_{0 \mathrm{~h}}$ or $k B^{-1}$ schemes. Then, selected $z_{0 \mathrm{~m}}$ and $z_{0 \mathrm{~h}}$ schemes are implemented within the Noah LSM to evaluate their performance in simulating the surface energy balance and soil temperature. Finally, the impact of $T_{\mathrm{sfc}}$ calculation and energy balance closure associated with measurement uncertainties on above assessment are discussed, and the selection of the appropriate $z_{0 \mathrm{~h}}$ scheme for applications is addressed.

\section{Field site and observations}

The Maqu climatic and environmental observation station (Fig. 1) is located in Maqu County, in the southeastern part of the SRYR that produces more than $54 \%$ of the total runoff over the SRYR. The elevation in this region varies from 3200 to $4200 \mathrm{~m}$ above mean sea level, and the climate 


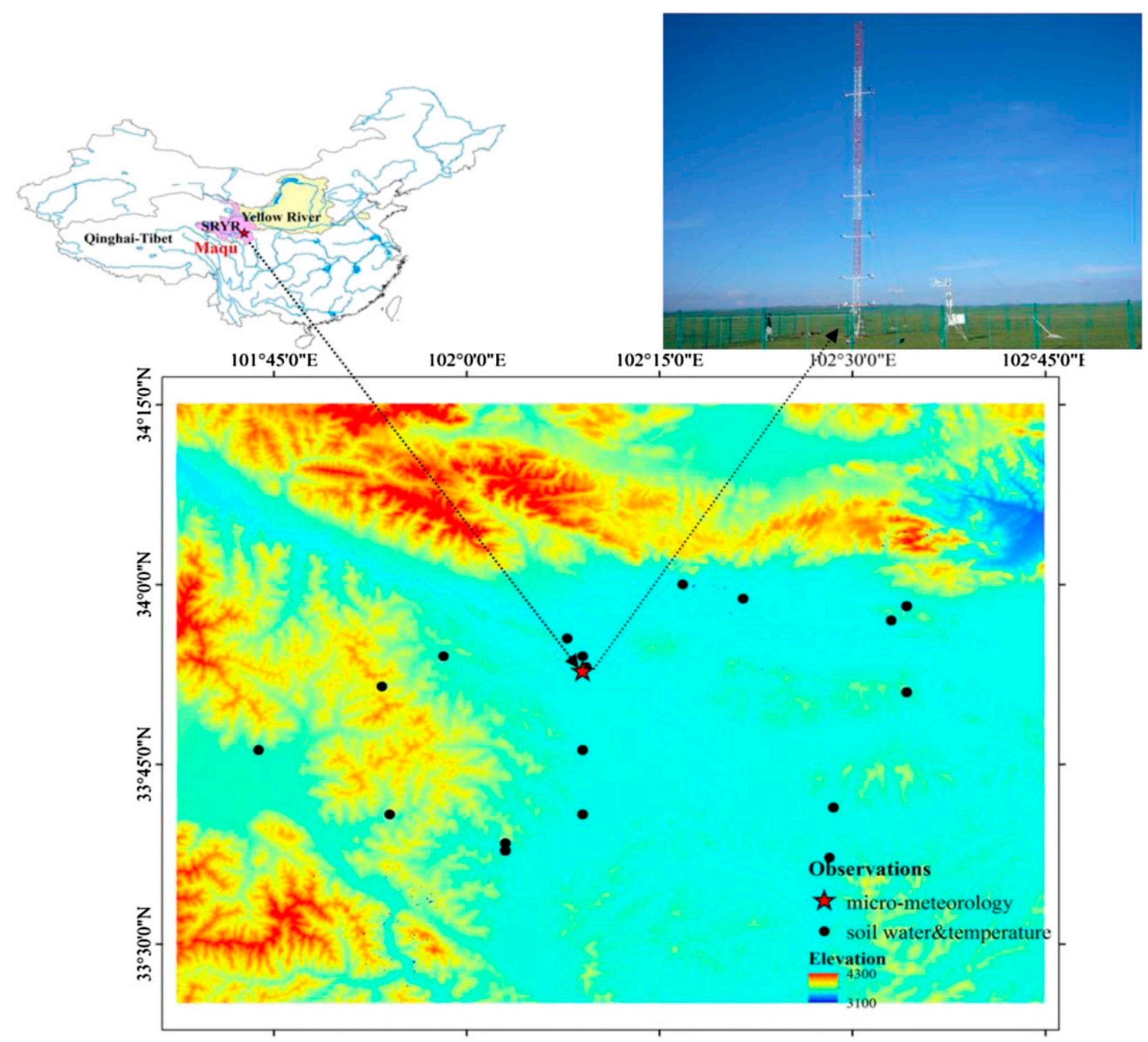

FIG. 1. (top left) Location of Maqu station (red star) over the SRYR (pink polygon) in China and (top right) the micrometeorological observation system, as well as the soil moisture and soil temperature monitoring network equipment at the station. (bottom) Elevation map of the station as well as the soil and temperature stations.

is characterized by dry cold winters and rainy summers. The annual mean air temperature is $1.2^{\circ} \mathrm{C}$, and the mean temperatures of the coldest month (January) and warmest month (July) are $-10^{\circ}$ and $11.7^{\circ} \mathrm{C}$, respectively. The alpine meadow species (e.g., Cyperaceae and Gramineae) are the main components of land cover, and they have a height of $15 \mathrm{~cm}$ during summers and about $5 \mathrm{~cm}$ during winters. The Maqu station is equipped with a micrometeorological observation system and a combined soil moisture and soil temperature monitoring network. The data used in this study have been collected at the micrometeorological observation system from 20 May 2009 to 17 May 2010. The episodes with snow on the ground are excluded by using only the data records for which the observed albedo attains the value of a snow-free surface. The information about the soil moisture and soil temperature monitoring network can be found in Su et al. (2011) and Dente et al. (2012). The soil starts freezing around the beginning of November, while the frozen ground totally thawed around the beginning of May.

The data from the micrometeorological observation system include measurements collected at a 20-m-high PBL tower and a 3.2-m-high EC system. The PBL tower was built on a flat and homogeneous area, and the EC system was set up nearby (Fig. 1). The EC system consisted of 1) a three-dimensional sonic anemometer (CSAT3, Campbell) measuring the high-frequency wind 
velocity in the $x, y$, and $z$ direction and the sonic temperature and 2) an open-path infrared gas analyzer (LI-7500, LI-COR) measuring the high-frequency $\mathrm{H}_{2} \mathrm{O}$ and $\mathrm{CO}_{2}$ concentrations. The sampling rate was $10 \mathrm{~Hz}$. A detailed description of the installment of the EC system and data processing [e.g., calculation of $H$, latent heat flux (LE), and $u_{*}$ ] can be found in Wang et al. (2013). Other supporting slow response measurements set at the PBL tower include five-level $(18.15,10.13,7.17,4.2$, and $2.35 \mathrm{~m})$ wind speed and direction, air temperature and humidity, radiation components (upward and downward shortwave/ longwave radiations), six-level (0.05, 0.1, 0.2, 0.4, 0.8, and $1.6 \mathrm{~m})$ soil moisture and soil temperature, and four-level soil heat flux $(0.075,0.15,0.3$, and $0.6 \mathrm{~m})$ measurements under the tower. All these slow response signals were sampled every $30 \mathrm{~s}$, and all the data were processed to a 30min interval. More information about the micrometeorological observation system can be also found in $\mathrm{Li}$ et al. (2009) and on the website (http://maqu.casnw.net).

The ground surface temperature was computed from measured upward and downward longwave radiations using the Stefan-Boltzmann equation:

$$
\varepsilon \sigma T_{\mathrm{sfc}}^{4}=L \uparrow-(1-\varepsilon) L \downarrow
$$

where $T_{\text {sfc }}$ is the ground surface temperature (K); $L^{\uparrow}$ and $L \downarrow$ are the upward and downward longwave radiation $\left(\mathrm{W} \mathrm{m}^{-2}\right)$, respectively; $\varepsilon$ is the surface emissivity; and $\sigma$ is the Stefan-Boltzmann constant (taken as $5.67 \times$ $10^{-8} \mathrm{~W} \mathrm{~m}^{-2} \mathrm{~K}^{4}$ ). In this study, the surface emissivity was taken as 0.95 for bare ground (November-April) and 0.98 for grassland (May-October; Brutsaert 1982).

\section{Theory and methodology}

\section{a. Surface heat flux simulation}

Surface heat flux transfer between the land surface and atmosphere is usually described with bulk equations based on the MOST (e.g., Chen et al. 1997; van den Hurk and Holtslag 1997; Su et al. 2001; Y08):

$$
H=\rho c_{p} C_{h} u\left(\theta_{s}-\theta_{a}\right),
$$

$$
C_{h}=\frac{\kappa^{2} / R}{\left[\ln \left(\frac{z}{z_{0 \mathrm{~m}}}\right)-\Psi_{m}\left(\frac{z}{L}\right)+\Psi_{m}\left(\frac{z_{0 \mathrm{~m}}}{L}\right)\right]\left[\ln \left(\frac{z}{z_{0 \mathrm{~h}}}\right)-\Psi_{h}\left(\frac{z}{L}\right)+\Psi_{h}\left(\frac{z_{0 \mathrm{~h}}}{L}\right)\right]},
$$

$$
\begin{gathered}
L=-\frac{\rho c_{p} u_{*}^{3} \theta_{a}}{\kappa g H}, \\
u_{*}^{2}=C_{m} \times u^{2},
\end{gathered}
$$

and

$$
C_{m}=\frac{\kappa^{2}}{\left[\ln \left(\frac{z}{z_{0 \mathrm{~m}}}\right)-\Psi_{m}\left(\frac{z}{L}\right)+\Psi_{m}\left(\frac{z_{0 \mathrm{~m}}}{L}\right)\right]^{2}}
$$

where $H$ is the sensible heat flux $\left(\mathrm{W} \mathrm{m}^{-2}\right) ; \rho$ is the density of air $\left(\mathrm{kg} \mathrm{m}^{-3}\right) ; c_{p}$ is the specific heat of air $\left(\mathrm{J} \mathrm{kg}^{-1} \mathrm{~K}^{-1}\right) ; C_{h}$ is the surface exchange coefficient for heat transfer; $u$ is the mean wind speed $\left(\mathrm{m} \mathrm{s}^{-1}\right) ; \theta_{s}$ is the potential temperature at the surface $(\mathrm{K}) ; \theta_{a}$ is the potential air temperature $(\mathrm{K}) ; \kappa$ is the von Kármán constant (taken as 0.4); $R$ is related to the turbulent Prandtl number $(\operatorname{Pr})$ and taken as 1.0; $z$ is the observation height (m); $z_{0 \mathrm{~m}}$ is the roughness length for momentum transfer (m); $z_{0 \mathrm{~h}}$ is the roughness length for heat transfer $(\mathrm{m}) ; \Psi_{m}$ and $\Psi_{h}$ are the stability correction function for momentum and sensible heat transfer, respectively; $L$ is the
Obukhov length $(\mathrm{m}) ; u_{*}$ is the friction velocity $\left(\mathrm{m} \mathrm{s}^{-1}\right)$; $g$ is the gravity acceleration $\left(\mathrm{m} \mathrm{s}^{-2}\right)$; and $C_{m}$ is the surface exchange coefficient for momentum transfer. The above bulk MOST equations also form the basis for the sensible heat flux calculations by the Noah LSM (Chen et al. 1997).

\section{b. Estimation and parameterization of roughness lengths}

Clearly, the roughness lengths $z_{0 \mathrm{~m}}$ and $z_{0 \mathrm{~h}}$ are crucial to determine $H$ using bulk MOST Eqs. (2a)-(2e). Their values are ideally estimated through application of the inverse bulk MOST equations with the in situ surface heat fluxes and profile measurements of wind, temperature, and humidity. However, such measurements are typically not available for large spatial domains. Various $z_{0 \mathrm{~m}}$ and $z_{0 \mathrm{~h}}$ schemes have, therefore, been proposed that relate the respective roughness lengths to global land cover and vegetation databases allowing large-scale $H$ simulations. In the text below, several schemes of roughness lengths proposed for the Noah LSM are briefly introduced, and the methods to derive the values for $z_{0 \mathrm{~m}}, z_{0 \mathrm{~h}}$, and $k B^{-1}$ using the in situ surface heat fluxes and profile data are described as well. 
TABLE 1. Four parameterizations of roughness lengths $(\mathrm{m})$ selected for this study: $\mathrm{GVF}_{\mathrm{norm}}=(\mathrm{GVF}-\mathrm{GVF}$ min $) /\left(\mathrm{GVF}_{\max }-\mathrm{GVF}\right.$ min $)$, $z_{0 \mathrm{~m}}^{\prime}$ is the effective momentum roughness length $(\mathrm{m}), z_{0 \mathrm{~g}}$ is the momentum roughness length for bare soil $(\mathrm{m})$, and $\theta_{*}=\left(\theta_{a} u_{*}^{2}\right) /(\kappa g L)$.

\begin{tabular}{|c|c|c|}
\hline Formulation & Reference/source & Abbreviation \\
\hline $\begin{array}{l}z_{0 \mathrm{~m}}=0.035 \text { for grassland, } z_{0 \mathrm{~m}}=0.011 \text { for bare soil } \\
z_{0 \mathrm{~h}}=z_{0 \mathrm{~m}} \exp \left(-0.1 \kappa \sqrt{u_{*} z_{0 \mathrm{~m}} / \nu}\right)\end{array}$ & Zilitinkevich (1995)/Noah 2.7.1 & $\mathrm{N} 2.7$ \\
\hline $\begin{array}{l}z_{0 \mathrm{~m}}=\left(1-\mathrm{GVF}_{\text {norm }}\right) z_{0 \mathrm{~m}, \min }+\mathrm{GVF}_{\text {norm }} z_{0 \mathrm{~m}, \max } \\
z_{0 \mathrm{~h}}=z_{0 \mathrm{~m}} \exp \left(-10^{-0.4 z_{0 \mathrm{~m}} / 0.07 k} \sqrt{u_{*} z_{0 \mathrm{~m}} / \nu}\right)\end{array}$ & Chen and Zhang (2009)/Noah 3.4.1 & $\mathrm{N} 3.4$ \\
\hline $\begin{array}{l}z_{0 \mathrm{~m}}^{\prime}=\exp \left\{(1-\mathrm{GVF})^{2} \ln \left(z_{0 \mathrm{~g}}\right)+\left[1-(1-\mathrm{GVF})^{2}\right] \ln \left(z_{0 \mathrm{~m}}\right)\right\} \\
z_{0 \mathrm{~h}}=z_{0 \mathrm{~m}}^{\prime} \exp \left[-0.8(1-\mathrm{GVF})^{2} \kappa \sqrt{u_{*} z_{0 \mathrm{~g}} / \nu}\right]\end{array}$ & Zheng et al. (2012) & $\mathrm{Z} 12$ \\
\hline$z_{0 \mathrm{~h}}=\left(70 \nu / u_{*}\right) \exp \left(-7.2 u_{*}^{0.5}\left|\theta_{*}\right|^{0.25}\right)$ & Yang et al. (2008) & Y08 \\
\hline
\end{tabular}

\section{1) Parameterization of Roughness Lengths FOR NOAH LSM}

Four roughness length schemes that have previously been utilized within the Noah LSM (Chen et al. 1997; Chen and Zhang 2009; Chen et al. 2011; Z12) are selected for this study. In version 2.7.1 of Noah (N2.7), the $z_{0 \mathrm{~m}}$ is defined as a function of land cover (specified as $0.035 \mathrm{~m}$ for grassland and $0.011 \mathrm{~m}$ for bare soil), and the Reynolds number-dependent formulation proposed by Zilitinkevich (1995) is implemented for the $z_{0 \mathrm{~h}}$ calculation (Chen et al. 1997):

$$
z_{0 \mathrm{~h}}=z_{0 \mathrm{~m}} \exp \left(-\kappa C_{\mathrm{zil}} \sqrt{\mathrm{Re}_{*}}\right)
$$

and

$$
\mathrm{Re}_{*}=u_{*} z_{0 \mathrm{~m}} / \nu
$$

where $\nu$ is the kinematic molecular viscosity (taken as $\left.1.5 \times 10^{-5} \mathrm{~m}^{2} \mathrm{~s}^{-1}\right) . C_{\mathrm{zil}}$ is an empirical constant and specified as 0.1 in Noah 2.7.1 analogous to values derived from measurements over grassland.

In the latest version (version 3.4.1) of Noah (N3.4), seasonal values of $z_{0 \mathrm{~m}}$ are calculated based on GVF, and the Zilitinkevich (1995) empirical coefficient $C_{\mathrm{zil}}$ is computed as a function of canopy height via $z_{0 \mathrm{~m}}$ (Chen and Zhang 2009) using a relationship derived from 12 AmeriFlux datasets collected over a variety of land covers and climate regimes. Similar modifications have been proposed recently by Z12 to improve the cold bias in the daytime $T_{\text {sfc }}$ simulation over the arid western continental United States. Chen et al. (2010, 2011) reported on an alternative approach for improving the Noah's daytime $T_{\text {sfc }}$ simulation through implementation of the specific scheme for $z_{0 \mathrm{~h}}$ proposed by Y08.

The four parameterizations of roughness lengths are summarized in Table 1. Note that N2.7, N3.4, and Z12 have similar formulations for $z_{0 \mathrm{~h}}$ with different methods to specify the Zilitinkevich (1995) empirical coefficient $C_{\text {zil }}$. N2.7 utilizes a constant value $\left(C_{\mathrm{zil}}=0.1\right), \mathrm{N} 3.4$ defines it based on $z_{0 \mathrm{~m}}\left(C_{\mathrm{zil}}=10^{-0.4 z_{0 \mathrm{~m}} / 0.07}\right)$, and $\mathrm{Z} 12$ calculates it based on GVF $\left[C_{\mathrm{zil}} \approx(1-\mathrm{GVF})^{2} \times 0.8\right]$. Besides, both $\mathrm{N} 3.4$ and $\mathrm{Z} 12$ calculate the $z_{0 \mathrm{~m}}$ using GVF, but different schemes are used: N3.4 interpolates the values of $z_{0 \mathrm{~m}}$ linearly between a specified minimum $\left(z_{0 \mathrm{~m}, \mathrm{~min}}\right.$, equal to bare soil $z_{0 \mathrm{~m}}$ when $\left.\mathrm{GVF}=0\right)$ and maximum $\left(z_{0 \mathrm{~m} \text {,max }}\right.$, equal to fully vegetated $z_{0 \mathrm{~m}}$ when $\mathrm{GVF}=1) z_{0 \mathrm{~m}}$, while Z12 applies a quadric method to derive the effective momentum roughness length $\left(z_{0 \mathrm{~m}}\right)$ from the fully vegetated and bare soil $\left(z_{0 \mathrm{~g}}\right)$ to consider the convergence of $z_{0 \mathrm{~m}}$ in a model grid. The linear method in N3.4 and the quadric method in Z12 are similar as both obtain the GVF from satellite-derived NDVI data (Hong et al. 2009). The linear method tends to overestimate $z_{0 \mathrm{~m}}$ in sparse vegetated areas, while this overestimation can be minimized using the quadric method. The parameterization of Y08 is specific for the $z_{0 \mathrm{~h}}$ and does not depend on $z_{0 \mathrm{~m}}$, which is a combination of friction velocity $\left(u_{*}\right)$ and friction temperature $\left(\theta_{*}\right)$.

\section{2) EstimAtion OF ROUGHNESS LENGTHS}

Two methods (Sun 1999; Y08) are used in this study for estimation of monthly $z_{0 \mathrm{~m}}$ values from the profile measurements of wind $(u)$, temperature $\left(T_{a}\right)$, and humidity (RH) and single-level EC measurements of $u, T_{a}$, friction velocity $\left(u_{*}\right)$, and sensible heat flux $(H)$ collected at Maqu station. Following Sun (1999), the monthly $z_{0 \mathrm{~m}}$ is approximated from values derived from each 30-min observation interval with a linear least squares regression method. The monthly $z_{0 \mathrm{~m}}$ following Y08 is taken from the values associated with the highest occurrence within the histogram derived from the individual 30-min samples. A detailed description of both methods is provided in appendix A.

Given the obtained monthly $z_{0 \mathrm{~m}}$ values derived using either Y08's or Sun's (1999) approach, the thermal roughness length $z_{0 \mathrm{~h}}$ or $k B^{-1}$ is estimated through inversion of the bulk MOST Eqs. (2a)-(2e) using observed $H$ ( $\left.H_{\mathrm{obs}}\right)$ for each 30-min observation interval by following: 1 ) assume $\left.z_{0 \mathrm{~h}}=z_{0 \mathrm{~m}}, 2\right)$ calculate $H\left(H_{\text {cal }}\right)$ using 
Eqs. (2a)-(2e), 3) adjust $z_{0 \mathrm{~h}}$ according to the difference in $C_{h}$ if $\left.H_{\text {cal }} \neq H_{\text {obs }}, 4\right)$ repeat steps 2 and 3 until $H_{\text {cal }}=H_{\text {obs }}$, and 5) calculate $k B^{-1}$ as $k B^{-1}=\ln \left(z_{0 \mathrm{~m}} / z_{0 \mathrm{~h}}\right)$. For the five-level wind speed and air temperature profile measurements and one-level EC measurements, $k B^{-1}$ is calculated for each level, and their average is used in the analysis.

Similarly, the $k B^{-1}$ produced by the four $z_{0 \mathrm{~h}}$ schemes listed in Table 1 is calculated using the following steps: 1) assume $\left.k B^{-1}=0,2\right)$ derive the value of $z_{0 \mathrm{~h}}$ by $z_{0 \mathrm{~h}}=$ $\left.z_{0 \mathrm{~m}} \exp \left(k B^{-1}\right), 3\right)$ use $z_{0 \mathrm{~m}}$ and $z_{0 \mathrm{~h}}$ to calculate $u_{*}, \theta_{*}$, and $H_{\text {cal }}$ from Eqs. (2a)-(2e), 4) use $u_{*}$ and $\theta_{*}$ to calculate $k B^{-1}$ from $k B^{-1}=\ln \left(z_{0 \mathrm{~m}} / z_{0 \mathrm{~h}}\right)$ according to each of the four $z_{0 \mathrm{~h}}$ schemes, and 5) repeat steps 2-4 until the cost function $J=\sum_{i=1}^{6}\left(H_{\mathrm{cal}, i}-H_{\mathrm{obs}}\right)^{2}$ is minimized.

\section{c. Noah LSM}

The Noah LSM is widely used and forms the land component of the regional and global weather forecasting models at the National Centers for Environmental Prediction (NCEP) and of the Weather Research and Forecasting model (WRF) at the National Center for Atmospheric Research (NCAR). It originates from the Oregon State University (OSU) LSM and includes a Penman approach for the calculation of the latent heat flux (Mahrt and Ek 1984), a simple canopy model (Pan and Mahrt 1987), a four-layer soil model with thermal conduction equations for simulating the soil heat transport, and the diffusivity form of Richards's equation for soil water transport (Mahrt and Pan 1984), as well as a modestly complex canopy resistance scheme (Chen et al. 1996) and cold season physics (Koren et al. 1999). The simulation of $H$ in Noah was described in section 3a. More detailed information about this land surface model can be found in appendix B; the readers are also referred to existing literature (e.g., Ek et al. 2003; van der Velde et al. 2009; Niu et al. 2011).

We presently employ version 3.4.1 of the Noah LSM, and the codes are revised to utilize the measured upward shortwave radiation. The model is forced by the meteorological measurements collected at the PBL tower, such as air temperature, relative humidity, wind speed, air pressure, downward and upward shortwave radiations, downward longwave radiation, and precipitation. The vegetation type is prescribed as grassland at the Maqu station, and the soil type is set as silt loam based on Dente et al. (2012). The corresponding vegetation parameters (e.g., root depths) and soil hydraulic and thermal parameters are obtained from the default database of Noah. A monthly GVF database is used by Noah as default, which Gutman and Ignatov (1998) based on the 5-yr (1985-90) Advanced Very High Resolution Radiometer (AVHRR) NDVI data. Jiang et al. (2009) pointed out, however, that the GVF climatology cannot capture the real-time vegetation status. Therefore, the GVF data for Maqu station in this study have been derived from 200910 Satellite Pour l'Observation de la Terre (SPOT) 10daily synthesis NDVI products by following

$$
\mathrm{GVF}=\frac{\mathrm{NDVI}-\mathrm{NDVI}_{\min }}{\mathrm{NDVI}_{\max }-\mathrm{NDVI}_{\min }},
$$

where $\mathrm{NDVI}_{\text {min }}$ is minimum NDVI (or bare soil NDVI) and $\mathrm{NDVI}_{\max }$ is maximum NDVI (or full canopy NDVI). The values of $\mathrm{NDVI}_{\min }$ and $\mathrm{NDVI}_{\max }$ are specified as 0.8 and 0.1 respectively. A detailed description of the NDVI products and data processing can be found in Chen et al. (2013).

Application of Noah in a default mode accommodates four soil layers with thicknesses of 0.1, 0.3, 0.6, and $1.0 \mathrm{~m}$, respectively. The initial conditions of surface temperature and temperature in each layer are specified based on the measurements. The model-simulated soil temperatures, LE, and $H$ will be compared with the measurements to evaluate the skill of the selected roughness length schemes.

\section{d. Specific settings for the assessment}

To assess the performance of the various roughness length schemes (shown in Table 1) for Maqu station for different seasons, three specific procedures are carried out step by step. First, the monthly variations of $z_{0 \mathrm{~m}}$ and diurnal variations of $z_{0 \mathrm{~h}}$ are derived from the EC and profile measurements with the methods described in section $3 \mathrm{~b}$. These values are then utilized to assess the skill of those $z_{0 \mathrm{~h}}$ and $z_{0 \mathrm{~m}}$ schemes in reproducing the observed $z_{0 \mathrm{~h}}$ and $z_{0 \mathrm{~m}}$. In particular, the comparison between the observed $k B^{-1}\left[k B^{-1}=\ln \left(z_{0 \mathrm{~m}} / z_{0 \mathrm{~h}}\right)\right]$ and the calculated $k B^{-1}$ with the $z_{0 \mathrm{~h}}$ schemes is carried out for three periods: 1) 15 December 2009 to 15 January 2010 (winter period), when soils are continuously frozen; 2) 8 April to 7 May 2010 (spring period), when soils are in transition from being frozen to thaw; and 3) 1 to 30 September 2009 (monsoon period), when soils are completely thawed and vegetation is active.

Second, the bulk MOST equations [Eqs. (2a)-(2e)] are used to assess the performance of various roughness length schemes in estimating $H$. Observed air temperature, relative humidity, and air pressure at $2.35 \mathrm{~m}$ from the PBL tower and wind speed at $3.2 \mathrm{~m}$ from the EC system, as well as $T_{\text {sfc }}$ derived from the observed longwave radiations (Eq. 1), are used within the bulk MOST calculations.

Finally, the selected $z_{0 \mathrm{~m}}$ and $z_{0 \mathrm{~h}}$ schemes are implemented within the Noah LSM to evaluate the $H$ and $T_{\text {sfc }}$, as well as LE and soil temperature simulations 

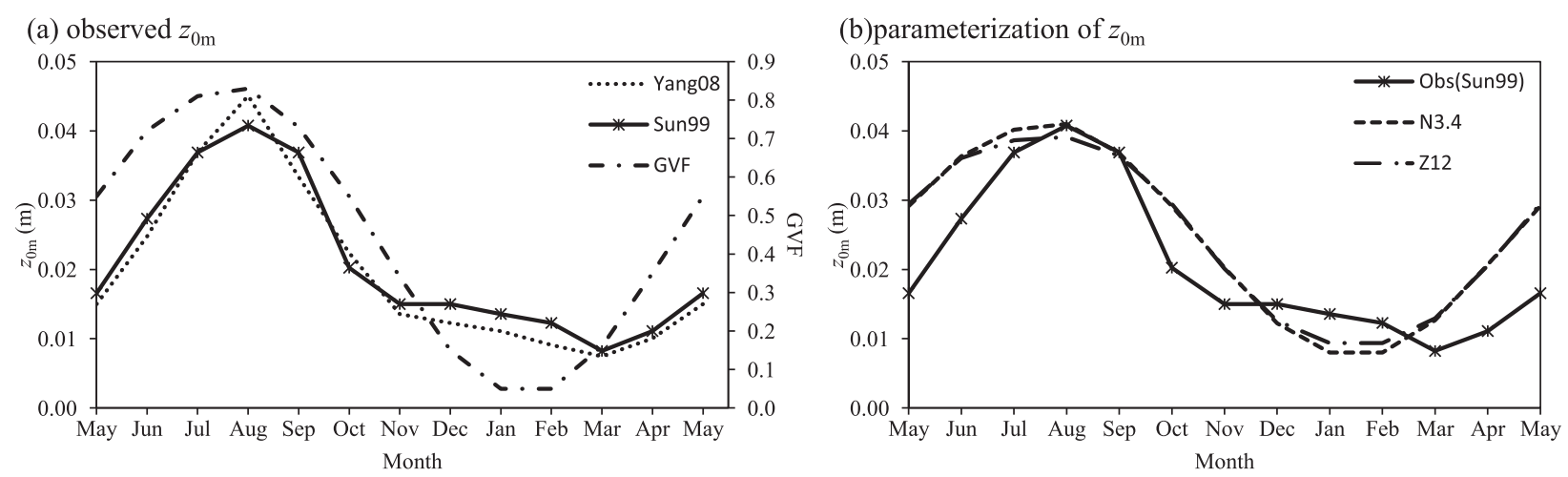

FIG. 2. Comparison of the monthly variations of $z_{0 \mathrm{~m}}$ (a) derived using methods from Y08's and Sun's (1999) and (b) from observations (Sun99) and two $z_{0 \mathrm{~m}}$ schemes (N3.4 and Z12).

against measurements. The model settings and input have been described in detail in section 3c.

\section{Results}

\section{a. Characteristics and parameterizations of roughness lengths}

\section{1) Momentum Roughness Length}

Figure $2 \mathrm{a}$ shows the monthly variations of $z_{0 \mathrm{~m}}$ obtained via Y08's and Sun's (1999) methods (see section $3 \mathrm{~b})$. It is noted that both methods produce similar monthly $z_{0 \mathrm{~m}}$ values and the order of magnitude varies from 0.007 to $0.045 \mathrm{~m}$. The monthly $z_{0 \mathrm{~m}}$ increases from the premonsoon period (May-June) to the monsoon period (July-September) and reaches its peak in August, then drops from August to the cold season (NovemberApril), achieving its minimum in March. The explanation for these seasonal variations can be that the surface is covered with sparse short grass over the Maqu station during the cold season, and it is partially covered with tall grass during the warm season (May-October). Since the $z_{0 \mathrm{~m}}$ is related to the surface conditions and canopy heights, the dynamics of GVF and canopy heights will change the values of $z_{0 \mathrm{~m}}$, as can be noted in Fig. 2a. On the other hand, it is also well known that the $z_{0 \mathrm{~m}}$ over smooth surfaces (e.g., plane and regular ice surface) is lower than bluff surfaces (e.g., grassland; Brutsaert 1982). Hence, it may also be expected that the $z_{0 \mathrm{~m}}$ is lower throughout winters because soil water is typically frozen during the cold season, as noted in Fig. 2a from November to April. It is, therefore, suggested to include the vegetation dynamics and consider soil water state in the parameterization of $z_{0 \mathrm{~m}}$ for seasonally frozen areas.

Figure $2 \mathrm{a}$ also shows that the derived value of $z_{0 \mathrm{~m}}$ for sparse short grass during the cold season [e.g., $z_{0 \mathrm{~m}}=$ $0.008 \mathrm{~m}$ in March by Sun (1999)] is comparable to the one prescribed in $\mathrm{N} 2.7$ for bare soil $\left(z_{0 \mathrm{~m}}=0.011 \mathrm{~m}\right.$ in Table 1). The value for tall grass with dense GVF during the warm season [e.g., $z_{0 \mathrm{~m}}=0.041 \mathrm{~m}$ in August by Sun (1999)] is somewhat higher than the one prescribed in $\mathrm{N} 2.7$ for grassland $\left(z_{0 \mathrm{~m}}=0.035 \mathrm{~m}\right)$. The values of $z_{0 \mathrm{~m}}$ calculated by N3.4 and Z12 $z_{0 \mathrm{~m}}$ schemes are shown in Fig. $2 \mathrm{~b}$. For this study, the values for $z_{0 \mathrm{mmin}}$ and $z_{0 \mathrm{mmax}}$ of the N3.4 scheme are set to 0.008 and $0.041 \mathrm{~m}$, respectively, and the values for $z_{0 \mathrm{~g}}$ and $z_{0 \mathrm{~m}}$ in $\mathrm{Z12}$ are taken as 0.008 and $0.041 \mathrm{~m}$, respectively. Figure $2 \mathrm{~b}$ illustrates that both $\mathrm{N} 2.7$ and Z12 produce similar values and capture the trend of $z_{0 \mathrm{~m}}$ derived from the measurements [in this case following Sun (1999)] reasonable well. Both schemes largely depend on the GVF dynamics. However, the linear method adopted in N3.4 produces higher $z_{0 \mathrm{~m}}$ for tall grass with dense GVF and lower $z_{0 \mathrm{~m}}$ for sparse short grass than the quadric method used in Z12.

\section{2) Thermal Roughness Length OR $K B^{-1}$}

Figure 3 shows the average composite diurnal variations of observed $k B^{-1}$ derived from the EC and profile measurements for Maqu station for three typical periods: a winter (15 December 2009 to 15 January 2010), a spring (8 April to 7 May 2010), and a monsoon period (1-30 September 2009). The observed $k B^{-1}$ exhibits apparent diurnal variations for each period, and negative values of $k B^{-1}$ occur during the night, particularly in the winter period (Fig. 3a). Verhoef et al. (1997) have also reported negative $k B^{-1}$ values for a nearly aerodynamically smooth bare soil surface. Ice exists when the ground surface is frozen during the winter period, and the surface during this period can be considered as aerodynamically smooth, which explains the negative $k B^{-1}$ values. Y08 found that negative values of $k B^{-1}$ are also often observed for aerodynamically rough surfaces, which may be attributed to heat transfer by inactive (nonlocal) eddies in the outer layer. 
(a)winter period

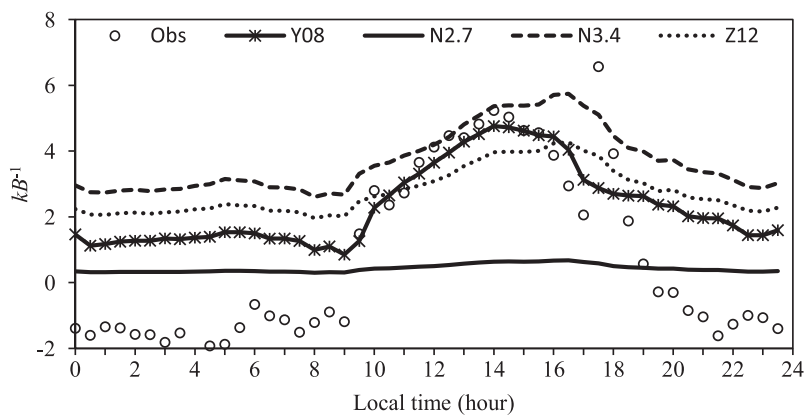

(c)monsoon period

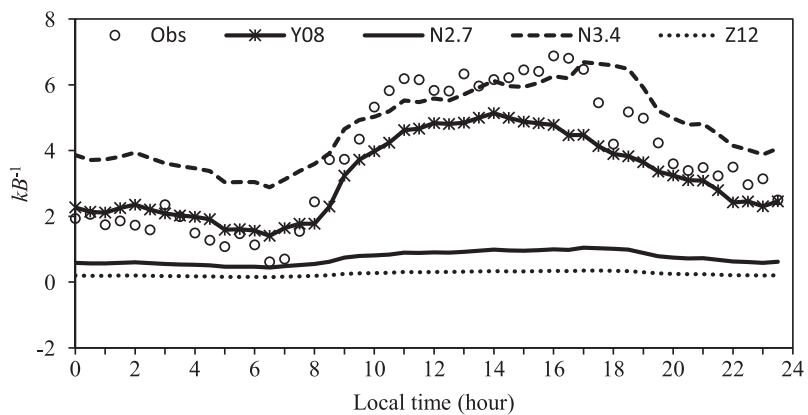

(b)spring period

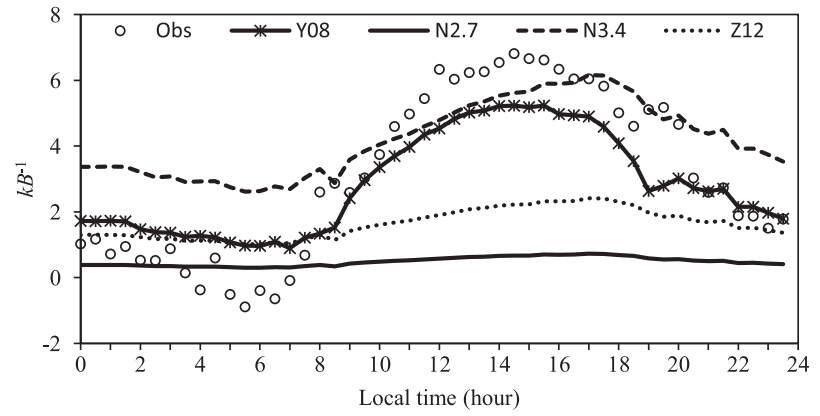

FIG. 3. Comparison of the average composite diurnal variations between the observed $k B^{-1}$ and four $k B^{-1}$ schemes (Y08, N2.7, N3.4, and Z12) during the (a) winter, (b) spring, and (c) monsoon periods.
Figure 3 also compares the average composite diurnal variations of the observed $k B^{-1}$ with the values calculated by four $k B^{-1}$ schemes. It shows that the $k B^{-1}$ schemes, except N2.7, can reproduce the diurnal variations well during the winter period (Fig. 3a). Both N3.4 $\left(C_{\mathrm{zil}}=10^{-0.4 z_{\mathrm{om}} / 0.07}\right)$ and $\mathrm{Z} 12\left[C_{\mathrm{zil}} \approx(1-\mathrm{GVF})^{2} \times 0.8\right]$ schemes produce comparable results, which indicates that the performance of $\mathrm{N} 2.7\left(C_{\mathrm{zil}}=0.1\right)$ can be improved by increasing the value of $C_{\text {zil }}$. Similar results have also been reported by Zeng et al. (2012) for arid regions. They recommended $C_{\text {zil }}=0.9$. Both N3.4 and Y08 can capture the diurnal variations for the spring and monsoon periods (Figs. 3b,c), whereas the variations produced by $\mathrm{Z} 12$ and $\mathrm{N} 2.7$ are very small. The reason for this is that the value of $C_{\mathrm{zil}}$ calculated by Z12 depends on the seasonally variable GVF, and the value of GVF during the spring $(\mathrm{GVF}=0.35$ in April) or monsoon $(\mathrm{GVF}=0.73$ in September) period is higher than the one during the winter period $(\mathrm{GVF}<0.2$ between December and March). As such, the value of $C_{\text {zil }}$ calculated by Z12 for the spring $\left(C_{\text {zil }} \approx 0.32\right.$ in April) or monsoon $\left(C_{\mathrm{zil}} \approx 0.06\right.$ in September) period decreases sharply as compared to the winter period $\left(C_{\text {zil }} \approx 0.72\right.$ in January). N3.4 produces a value of $C_{\mathrm{zil}}$ comparable to $\mathrm{Z} 12$ for the winter period $\left(C_{\mathrm{zil}} \approx 0.87\right.$ when $z_{0 \mathrm{~m}}=$ $0.01 \mathrm{~m}$ ), but it tends to produce a higher value of $C_{\mathrm{zil}}$ for the spring and monsoon periods $\left(C_{\mathrm{zil}} \approx 0.63\right.$ when $\left.z_{0 \mathrm{~m}}=0.035 \mathrm{~m}\right)$. This indicates that a relatively higher value of $C_{\mathrm{zil}}$ is recommended for the spring and monsoon periods where there is also a higher GVF.

Overall, Y08 and N3.4 perform better than other schemes, while Y08 produces a more distinct diurnal cycle and agrees better with the observed $k B^{-1}$, which is attributed to the use of the $\theta_{*}$ within the parameterization of $z_{0 \mathrm{~h}}(\mathrm{Y} 08)$. In addition, all the roughness length schemes tend to produce a better agreement with the observed $k B^{-1}$ during the day than during the night.

\section{b. Performance of roughness length schemes in simulating sensible heat flux \\ 1) Performance of thermal roughness LENGTH SCHEMES}

Given the observed $z_{0 \mathrm{~m}}$ values (shown in Fig. 2), the four $z_{0 \mathrm{~h}}$ schemes are also utilized for estimating the $H$ from the bulk MOST equations. Figure 4 compares the average composite diurnal variations of the measured $H$ and the calculations for the three periods. Overall, both N3.4 and Y08 schemes result in better agreements with the measured $H$ than others during daytime. The poorer performance of the $\mathrm{N} 2.7$ and Z12 schemes is caused by the much lower heat transfer resistances produced during the day because of the lower $C_{\text {zil }}$ value, which is the key toward improving the $H$ simulation.

Figure 4 shows further that the measured $H$ is higher during the winter and spring periods (Figs. 4a,b) than 

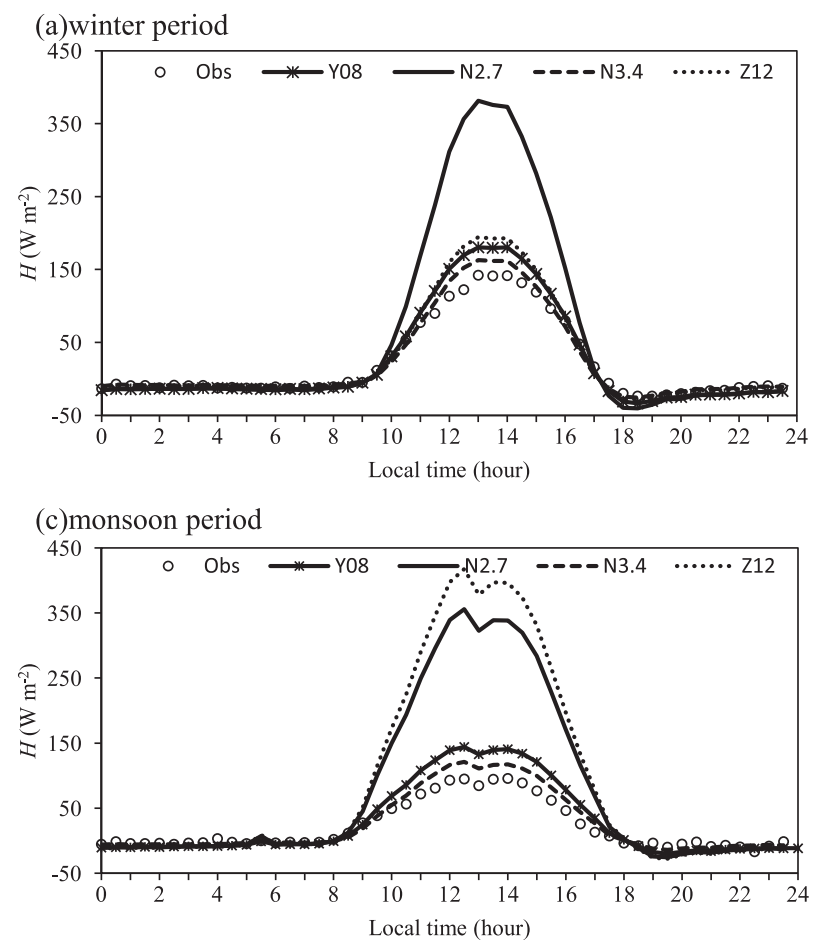

during the monsoon period (Fig. 4c). The explanation for this seasonal variation is that the sensible heat flux is the dominant component of the surface energy budget before the onset of monsoon (about the end of May to the middle of June), because conditions (e.g., soil moisture and temperature) for the production of latent heat are not favorable during those periods. After the onset of monsoon, the temperature and the available soil moisture content doubles the latent heat production with respect to the sensible heat, while the net radiation remains at the same level because of more cloud cover.

Table 2 provides the error statistics, such as coefficient of determination $\left(R^{2}\right)$, mean bias (MBE), and rootmean-squared error (RMSE), computed between the observed and simulated $H$, which also indicates that N3.4 and Y08 perform better for all three periods, while Z12 performs better than N2.7 only during the winter period. Therefore, the simulation of $H$ by the original Zilitinkevich (1995) $z_{0 \mathrm{~h}}$ scheme implemented in N2.7 (b)spring period

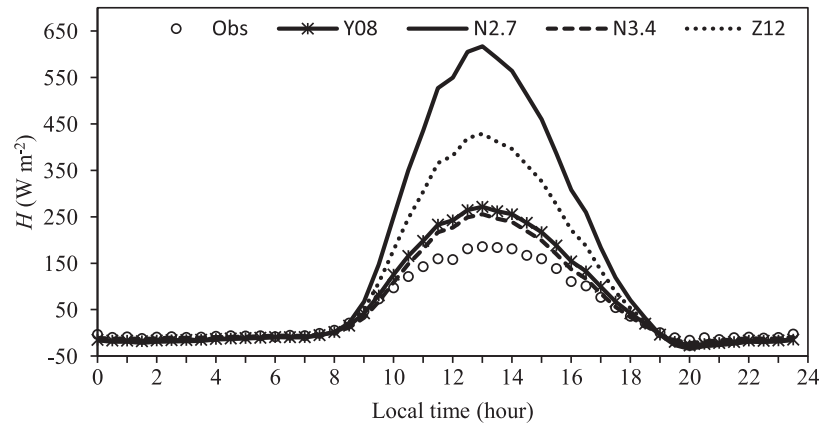

FIG. 4. As in Fig. 3, but for sensible heat flux.

can be improved by all three newly developed $z_{0 \mathrm{~h}}$ schemes (i.e., N3.4, Z12, and Y08), at least during the winter period. It should, however, be noted that for the spring and monsoon periods with higher GVF (GVF > 0.35 ), only $\mathrm{N} 3.4$ and $\mathrm{Y} 08$ produce better results than N2.7. The N3.4 and Y08 schemes will, therefore, be used for further analysis.

\section{2) Performance of MOMENTUM ROUGHNESS LENGTH SCHEMES}

The monthly $z_{0 \mathrm{~m}}$ variations shown in section $4 \mathrm{a}$ were attributed to vegetation dynamics and soil water state in seasonally frozen ground. Section $4 \mathrm{a}$ also showed that the current $z_{0 \mathrm{~m}}$ schemes (e.g., N3.4 and Z12 shown in Table 1) can reproduce comparable $z_{0 \mathrm{~m}}$ values and capture these $z_{0 \mathrm{~m}}$ dynamics. Therefore, we test the performance of three $z_{0 \mathrm{~m}}$ schemes in simulating $H$ : N2.7, $\mathrm{N} 3.4$, and Z12. In N2.7, the values of $z_{0 \mathrm{~m}}$ are specified as $0.035 \mathrm{~m}$ for the warm season (May-October) and

TABLE 2. Determination coefficient $\left(R^{2}\right)$, MBE, and RMSE between observed $H$ and simulations derived by the four $z_{0 \mathrm{~h}}$ schemes for the three typical periods.

\begin{tabular}{|c|c|c|c|c|c|c|c|c|c|}
\hline \multirow[b]{2}{*}{$z_{0 \mathrm{~h}}$} & \multicolumn{3}{|c|}{ Winter period } & \multicolumn{3}{|c|}{ Spring period } & \multicolumn{3}{|c|}{ Monsoon period } \\
\hline & $R^{2}$ & $\operatorname{MBE}\left(\mathrm{W} \mathrm{m}^{-2}\right)$ & $\operatorname{RMSE}\left(\mathrm{W} \mathrm{m}^{-2}\right)$ & $\overline{R^{2}}$ & $\operatorname{MBE}\left(\mathrm{W} \mathrm{m}^{-2}\right)$ & $\operatorname{RMSE}\left(\mathrm{W} \mathrm{m}^{-2}\right)$ & $\overline{R^{2}}$ & $\operatorname{MBE}\left(\mathrm{W} \mathrm{m}^{-2}\right)$ & $\operatorname{RMSE}\left(\mathrm{W} \mathrm{m}^{-2}\right)$ \\
\hline $\mathrm{N} 2.7$ & 0.90 & 38.36 & 95.7 & 0.93 & 65.24 & 141.0 & 0.91 & 54.71 & 123.1 \\
\hline N3.4 & 0.92 & 2.97 & 19.3 & 0.94 & 10.99 & 34.9 & 0.91 & 4.05 & 21.9 \\
\hline Z12 & 0.92 & 8.07 & 27.0 & 0.93 & 41.56 & 93.1 & 0.91 & 67.82 & 151.1 \\
\hline Y08 & 0.93 & 3.80 & 24.0 & 0.94 & 10.79 & 34.4 & 0.91 & 8.23 & 30.7 \\
\hline
\end{tabular}


TABLE 3. Comparative statistics between observed $H$ and simulations using three $z_{0 \mathrm{~m}}$ schemes for warm season and cold season respectively.

\begin{tabular}{|c|c|c|c|c|c|c|c|}
\hline \multirow[b]{2}{*}{$z_{0 \mathrm{~m}}$} & \multirow[b]{2}{*}{$z_{0 \mathrm{~h}}$} & \multicolumn{3}{|c|}{ Warm season } & \multicolumn{3}{|c|}{ Cold season } \\
\hline & & $R^{2}$ & $\operatorname{MBE}\left(\mathrm{W} \mathrm{m}^{-2}\right)$ & $\operatorname{RMSE}\left(\mathrm{W} \mathrm{m}^{-2}\right)$ & $R^{2}$ & $\operatorname{MBE}\left(\mathrm{Wm}^{-2}\right)$ & $\operatorname{RMSE}\left(\mathrm{W} \mathrm{m}^{-2}\right)$ \\
\hline \multirow[t]{2}{*}{$\mathrm{N} 2.7$} & N3.4 & 0.89 & 4.92 & 32.8 & 0.92 & 8.23 & 38.9 \\
\hline & Y08 & 0.89 & 10.02 & 42.5 & 0.93 & 10.67 & 45.5 \\
\hline \multirow[t]{2}{*}{ N3.4 } & N3.4 & 0.89 & 5.17 & 33.5 & 0.92 & 8.35 & 39.1 \\
\hline & Y08 & 0.89 & 10.17 & 42.9 & 0.93 & 11.27 & 43.4 \\
\hline \multirow[t]{2}{*}{$\mathrm{Z} 12$} & N3.4 & 0.89 & 5.08 & 33.3 & 0.92 & 8.33 & 39.1 \\
\hline & Y08 & 0.89 & 10.11 & 42.8 & 0.93 & 11.40 & 47.6 \\
\hline
\end{tabular}

$0.011 \mathrm{~m}$ for the cold season (November-April), and the settings of N3.4 and Z12 were previously introduced in section 4a. N3.4 and $\mathrm{Y} 08 z_{0 \mathrm{~h}}$ schemes are combined with these three $z_{0 \mathrm{~m}}$ schemes to investigate the better combination of $z_{0 \mathrm{~h}}$ and $z_{0 \mathrm{~m}}$ parameterizations.

Table 3 gives the error statistics (i.e., $R^{2}, \mathrm{MBE}$, and RMSE) between the observed and simulated $H$ for the warm season (May-October) and cold season (NovemberApril). Clearly, different $z_{0 \mathrm{~m}}$ schemes produce minor differences in simulating $H$, and the simulations are highly sensitive to the $z_{0 \mathrm{~h}}$ schemes and much less sensitive to the $z_{0 \mathrm{~m}}$ schemes.

In summary, the simulation of $H$ is much more sensitive to the $z_{0 \mathrm{~h}}$ schemes than the $z_{0 \mathrm{~m}}$ schemes, and N3.4 and $\mathrm{Y} 08 z_{0 \mathrm{~h}}$ schemes perform better than other schemes. Those newly developed $z_{0 \mathrm{~h}}$ schemes all provide better agreements with the measurements than the original N2.7 during the winter period with sparse GVF $(G V F<$ 0.2 between December and March). However, only N3.4 and Y08 $z_{0 \mathrm{~h}}$ schemes perform better during the monsoon period with much higher GVF (GVF $>0.70$ between June and September).

\section{c. Update of Noah LSM and evaluation}

As shown in section $4 \mathrm{~b}$, the simulation of $H$ is much more sensitive to the choice of the $z_{0 \mathrm{~h}}$ scheme than $z_{0 \mathrm{~m}}$ scheme, and N3.4 and Y08 $z_{0 \mathrm{~h}}$ schemes perform consistently better than other schemes. Therefore, both N3.4 and Y08 $z_{0 \mathrm{~h}}$ schemes are implemented within the Noah LSM to evaluate their performance in simulating the surface energy balance and soil temperature in comparison to the N2.7. The evaluation is carried out for the monsoon period (1-30 September 2009), and the codes are further revised to utilize the measured (liquid) soil moisture to prevent uncertainties associated with the soil water flow simulations from affecting the assessment. The simulations of $H, \mathrm{LE}$, and $T_{\mathrm{sfc}}$ are compared directly with the measurements, while the simulations of the soil temperature are interpolated to the measured depth.

Figure 5 compares the measured and simulated composite diurnal variations of heat fluxes and soil temperature obtained using the three $z_{0 \mathrm{~h}}$ schemes. It shows that the original Zilitinkevich (1995) $z_{0 \mathrm{~h}}$ scheme implemented in N2.7 strongly overestimates both measured $H$ and LE (Figs. 5a,b), which leads to less energy available for heating the surface and transporting to the deeper model layers (Figs. 5c,d). As a consequence, the surface temperature (Fig. 5e) and soil temperature at deeper layer (Figs. 5e,g) are strongly underestimated. Such overestimation of $H$ and LE by the original Zilitinkevich $z_{0 \mathrm{~h}}$ scheme can be significantly improved by implementing the $\mathrm{N} 3.4$ or Y $08 z_{0 \mathrm{~h}}$ scheme. Indeed, more realistic soil heat flux and soil temperature simulations are produced with both schemes.

Figure 5 shows also that the major difference between the measurements and simulations occurs during daytime. Table 4 gives the error statistics between the measured heat fluxes ( $H$ and $\mathrm{LE}), T_{\mathrm{sfc}}$, and soil temperature at $20 \mathrm{~cm}\left(T_{\mathrm{s} 20}\right)$ and the Noah simulations during the daytime (0900-1800 local time). Clearly, the simulations with the original Zilitinkevich (1995) $z_{0 \mathrm{~h}}$ scheme in N2.7 are significantly improved by implementing the N3.4 or Y08 $z_{0 \mathrm{~h}}$ scheme. The RMSEs between measured and simulated $H$, LE, $T_{\mathrm{sfc}}$, and $T_{\mathrm{s} 20}$ are reduced by about $28 \%, 29 \%, 61 \%$, and $70 \%$, respectively, using the N3.4 or Y08 $z_{0 \mathrm{~h}}$ scheme as compared to the N2.7, and the absolute MBEs are reduced by $29 \%, 79 \%$, $75 \%$, and $81 \%$, respectively.

\section{Discussion}

\section{a. Ground surface temperature uncertainty and its impact}

In section $4 \mathrm{~b}$, the bulk MOST equations [Eqs. (2a)(2e)] are used to assess the performance of various roughness length schemes in estimating sensible heat flux $(H)$, within which the ground surface temperature $\left(T_{\mathrm{sfc}}\right)$ is computed from measured longwave radiations [Eq. (1)]. Therefore, the uncertainty of groundbased longwave radiation measurements will affect the $T_{\text {sfc }}$ and $H$ estimates. The sensitivity of $T_{\text {sfc }}$ and $H$ to 


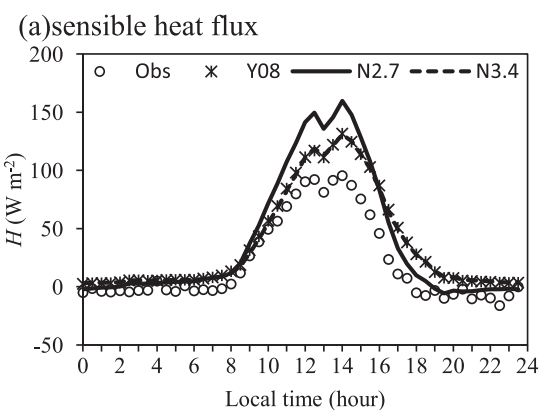

(b)latent heat flux

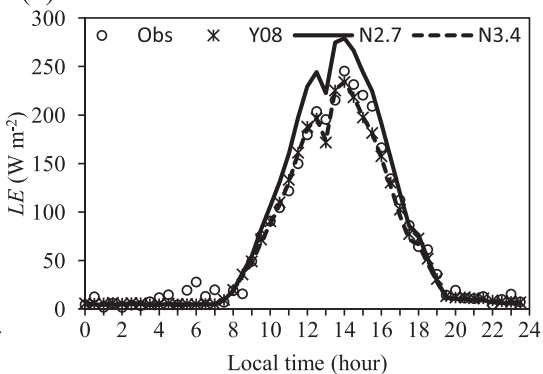

(d) soil heat flux at $30 \mathrm{~cm}$

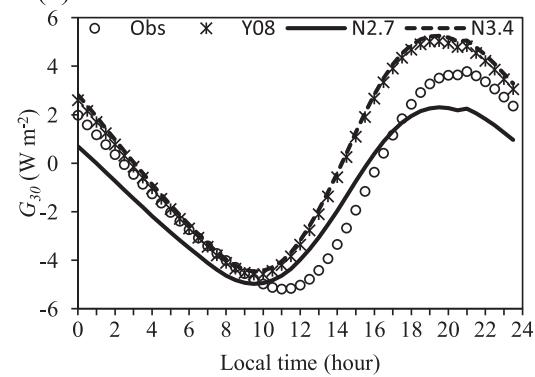

(g)soil temperature at $80 \mathrm{~cm}$

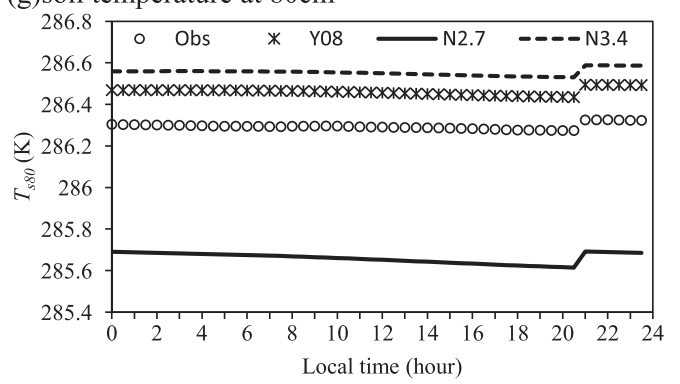

(e)surface temperature

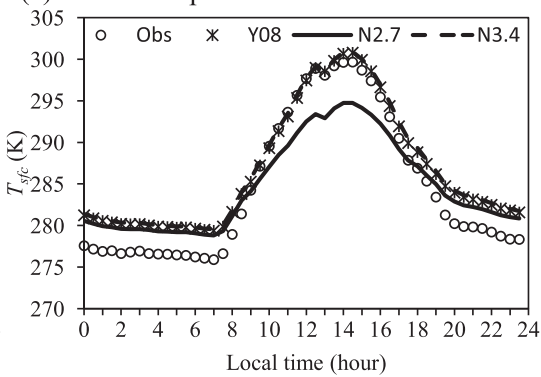

(c)surface soil heat flux

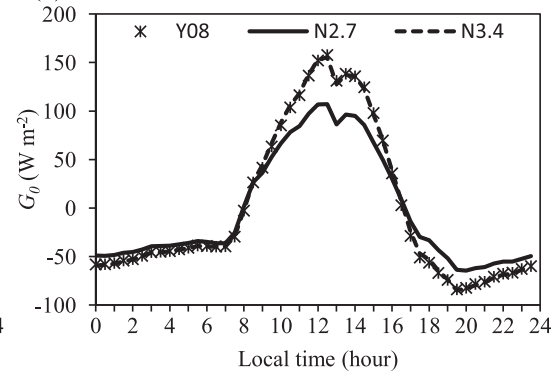

(f)soil temperature at $20 \mathrm{~cm}$

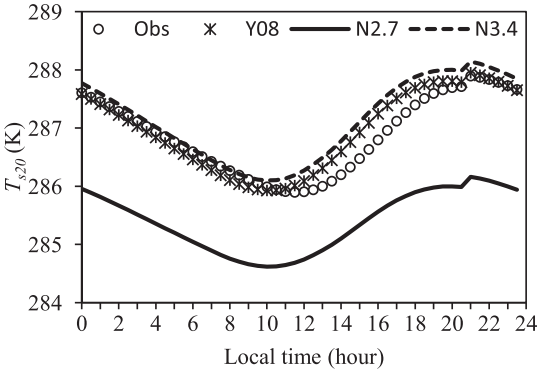

Local time (hour)

FIG. 5. Comparison of the average composite diurnal variations during the monsoon period between observations and the simulations derived by the Noah LSM using three $z_{0 \mathrm{~h}}$ schemes (Y08, N2.7, and N3.4) of: (a) sensible heat flux, (b) latent heat flux, (c) surface soil heat flux, (d) soil heat flux at $30 \mathrm{~cm}$, (e) surface temperature, and soil temperature at (f) $20 \mathrm{~cm}$ and (g) $80 \mathrm{~cm}$.

measurement uncertainties is tested by artificially adding $1 \%, 2 \%$, and $4 \%$ error to the longwave radiation during the daytime (0900-1800 local time), which corresponds to measurements with low, medium, and high uncertainty according Philipona et al. (2001) and Kohsiek et al. (2007).

The monsoon period (1-30 September 2009) is taken as an example for the sensitivity test and the three error levels results in a $T_{\text {sfc }}$ uncertainty of $0.29,0.59$, and $1.18 \mathrm{~K}$ during the daytime, respectively. The bulk MOST equations are then used in combination with these $T_{\text {sfc }}$ values to calculate $H$. Figure 6 shows the average composite diurnal variations of the measured $H$ and the calculations using N2.7 and N3.4 $z_{0 \mathrm{~h}}$ schemes. The plot illustrates that $4 \%$ decrease in the longwave radiation reduces the $H$ calculated at midday with $\mathrm{N} 2.7$ and N3.4 by 100 and $30 \mathrm{~W} \mathrm{~m}^{-2}$, respectively. Nevertheless, the N2.7 computed $H$ severely overestimates measurements (Fig. 6a), while the measurements fall within the ensemble of N3.4 $H$ computations (Fig. 6b). This is consistent with those findings in section 4 .

\section{b. Energy balance closure and its impact}

A well-known problem with surface heat flux measurements is the energy balance closure (Wilson et al. 2002; Massman and Lee 2002; Foken 2008), which is

TABLE 4. Comparative statistics between observed and simulated daytime (0900-1800 LT) heat fluxes and soil temperature states with Noah LSM obtained using three $z_{0 \mathrm{~h}}$ schemes during the monsoon period.

\begin{tabular}{|c|c|c|c|c|c|c|c|c|}
\hline \multirow[b]{2}{*}{$z_{0 \mathrm{~h}}$} & \multicolumn{2}{|c|}{$H\left(\mathrm{~W} \mathrm{~m}^{-2}\right)$} & \multicolumn{2}{|c|}{$\mathrm{LE}\left(\mathrm{W} \mathrm{m}^{-2}\right)$} & \multicolumn{2}{|c|}{$T_{\text {sfc }}(\mathrm{K})$} & \multicolumn{2}{|c|}{$T_{\mathrm{s} 20}(\mathrm{~K})$} \\
\hline & RMSE & MBE & RMSE & $\mathrm{MBE}$ & RMSE & $\mathrm{MBE}$ & RMSE & MBE \\
\hline $\mathrm{N} 2.7$ & 51.96 & 35.69 & 56.43 & 23.91 & 4.18 & -3.05 & 1.39 & -1.27 \\
\hline N3.4 & 37.27 & 25.08 & 39.61 & -6.94 & 1.83 & 1.08 & 0.52 & 0.42 \\
\hline Y08 & 38.32 & 25.97 & 40.63 & -4.90 & 1.62 & 0.76 & 0.41 & 0.24 \\
\hline
\end{tabular}



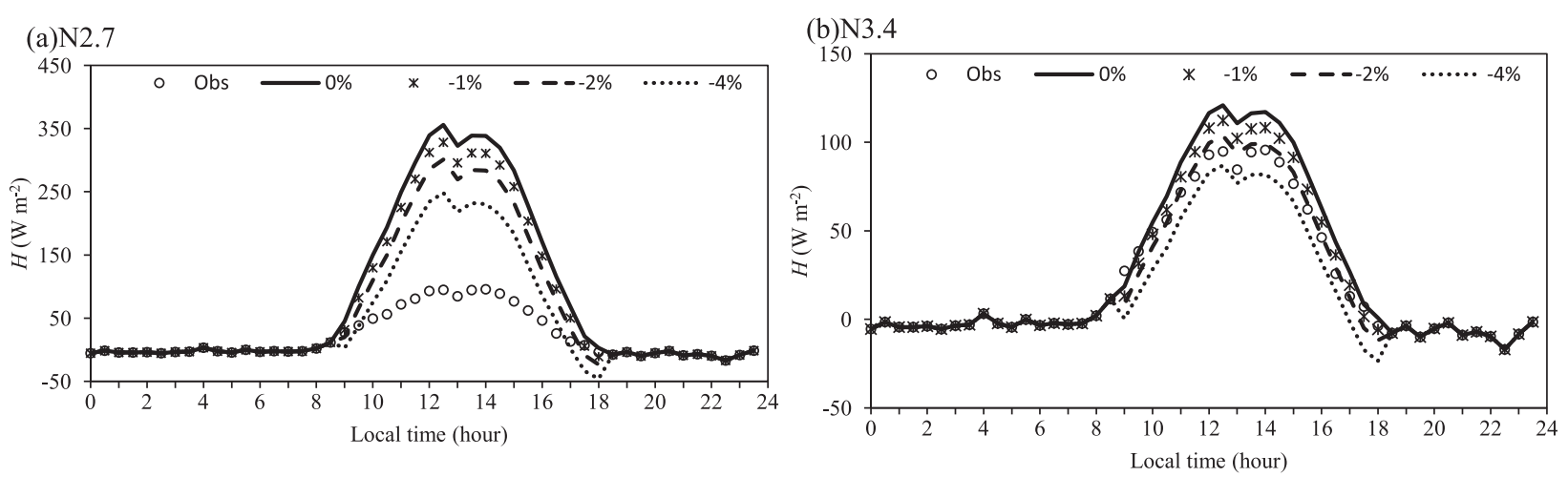

FIG. 6. Average composite $H$ diurnal variations for the monsoon from observations and simulated using the MOST equations with schemes (a) N2.7 and (b) N3.4 kB ${ }^{-1}$ with uncertainty levels imposed on longwave radiations of: $0,-1,-2$, and -44 percent.

particularly noticeable over the Tibetan Plateau (Tanaka et al. 2003; Yang et al. 2004). That is, the available energy, defined as the sum of net radiation $\left(R_{n}\right)$ and ground heat flux $\left(G_{0}\right)$, is larger than the sum of turbulent fluxes of sensible $(H)$ and latent (LE) heat. In most of the surface heat flux experiments, the error in the energy budget is less than 20\% (Foken 2008). Figure 7 shows the sum of turbulent heat fluxes plotted against the available energy for part of the monsoon (1-30 September 2009), where $G_{0}$ is calculated with the Noah LSM using N3.4 $z_{0 \mathrm{~h}}$ scheme. The closure ratio is high, with a value of around 0.88, as shown in Fig. 7.

Resolving the energy balance closure issue is beyond the scope of this study, and a detailed review of this problem can be found in Twine et al. (2000) and Foken (2008). However, the use of surface flux data to validate the land surface model requires that conservation of energy is satisfied, and the measured energy budget should be closed by some method (Twine et al. 2000). Twine et al. (2000) suggested that the closure can be most reasonably forced by assuming that the measured available energy $\left(R_{n}-G_{0}\right)$ is representative of the area, and thus, the measured turbulent fluxes $(H+\mathrm{LE})$ should be adjusted. The "Bowen ratio closure" method is used in this study, which assumes that the Bowen ratio is correctly measured by the EC system, so that the individual value of $H$ or $L E$ can be adjusted (Twine et al. 2000):

$$
\begin{aligned}
H_{\text {cor }} & =H+\operatorname{res} \times \frac{H}{H+\mathrm{LE}}, \\
\mathrm{LE}_{\mathrm{cor}} & =\mathrm{LE}+\operatorname{res} \times \frac{\mathrm{LE}}{H+\mathrm{LE}}, \quad \text { and }
\end{aligned}
$$

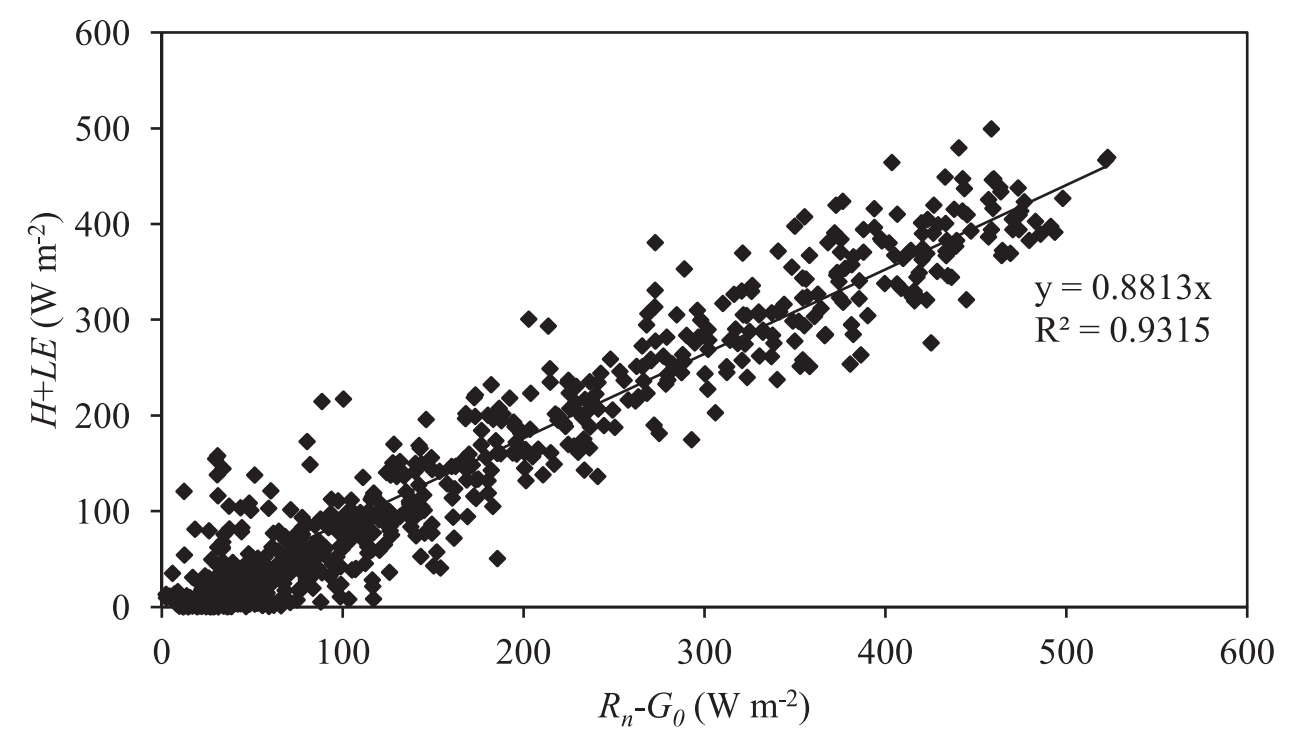

FIG. 7. A plot of the quantity $H+\operatorname{LE}$ vs $R_{n}-G_{0}$ showing energy balance closure of the surface fluxes over Maqu station during the monsoon period. 
(a) $\mathrm{kB}^{-1}$

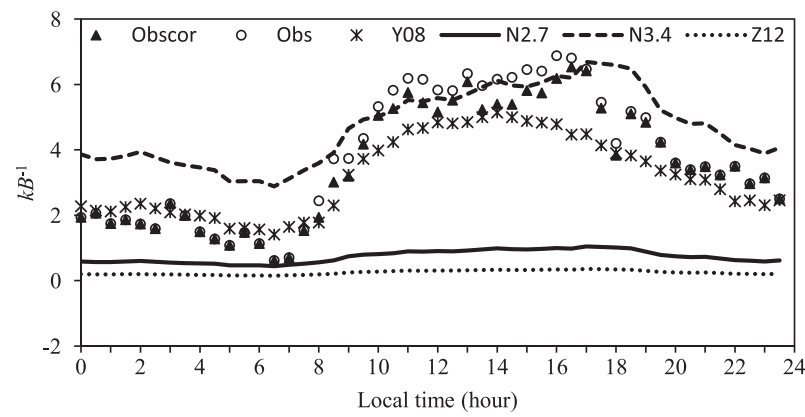

(c)latent heat flux

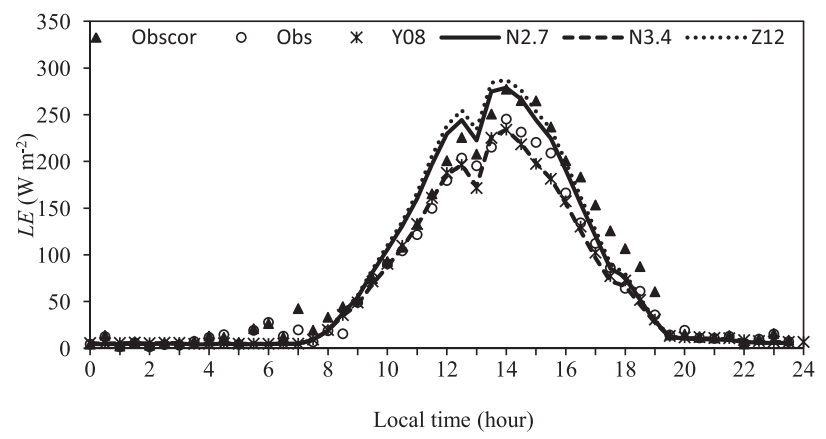

(b)sensible heat flux

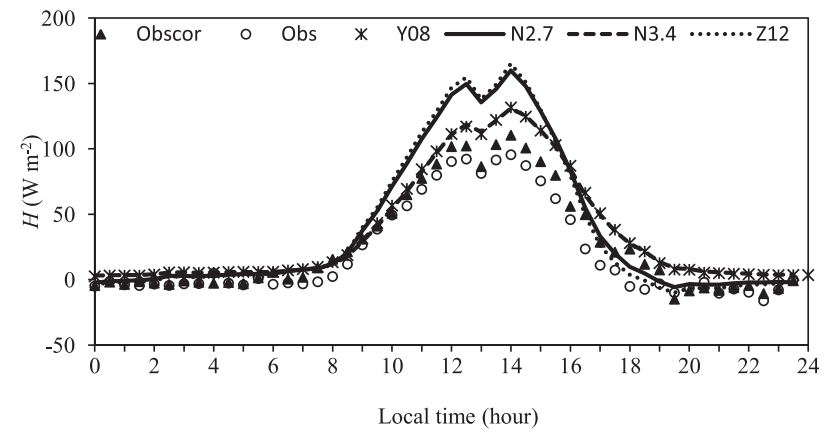

FIG. 8. Comparison of the average composite diurnal variations of (a) $k B^{-1}$, (b) sensible heat flux, and (c) latent heat flux between the original observations (obs), corrected observations ( $\mathrm{obs}_{\mathrm{cor}}$ ), and the simulations derived from the corrected observations using four $z_{0 \mathrm{~h}}$ schemes (Y08, N2.7, N3.4, and Z12) during the monsoon period.

$$
\text { res }=\left(R_{n}-G_{0}\right)-(H+\mathrm{LE})
$$

To test the impact of the closure of the energy budget on the aforementioned assessment of roughness length schemes (section 4), the corrected sensible heat flux $\left(H_{\text {cor }}\right)$ and latent heat flux $\left(\mathrm{LE}_{\text {cor }}\right)$ are used in combination with the Noah LSM and the other micrometeorological measurements to evaluate the impact of measurement uncertainty on the assessment of various $z_{0 h}$ or $k B^{-1}$ schemes. Figure 8 a shows the average composite diurnal variations of observed $k B^{-1}$ derived from the original and corrected sensible heat flux, while the values calculated by the four $k B^{-1}$ schemes with $H_{\text {cor }}$ are also shown. Figures $8 \mathrm{~b}$ and $8 \mathrm{c}$ compare the simulated $H$ and LE by Noah LSM using the four $z_{0 h}$ schemes with the original and corrected turbulent heat fluxes observations. Consistent with our findings in section 4, N3.4 and Y08 agree better with the corrected $k B^{-1}$ (Fig. 8a) and $H_{\text {cor }}$ observations (Fig. 8b) than N2.7 and Z12. However, we find that N3.4 and Y08 underestimate LE and perform poorer than N2.7 and Z12 when compared with $\mathrm{LE}_{\text {cor }}$ (Fig. 8c).

Although the comparison with $\mathrm{LE}_{\text {cor }}$ suggests that N2.7 and Z12 perform better than N3.4 and Y08, it should be noted that N2.7 and Z12 more severely overestimate the $H_{\text {cor }}$ (Fig. 8b) and underestimate the $T_{\text {sfc }}$ (Fig. 5d). The $\mathrm{LE}_{\text {cor }}$ underestimation by N3.4 and Y08 can be explained by the vegetation parameters prescribed in the Noah LSM. Indeed, van der Velde et al. (2009) have shown that, for the Maqu station on the central Tibetan Plateau, a LE underestimation can be mitigated via calibration of the minimum stomatal resistance and the optimum temperature for transpiration. However, the objective of this study is to analyze the impact of roughness length schemes in simulating heat fluxes and not to address the problem of LE simulation in detail. As such, it can be concluded that the assessments related to $k B^{-1}, H$, and soil temperature in section 4 are still valid if the measured energy budget is forced to be closed.

\section{c. Choice of $z_{0 \mathrm{~h}}$ scheme}

As seen in the previous sections, diurnal variations of $z_{0 h}$ are observed over Maqu station in different seasons, and a successful modeling of the variations is important for reliable $H$ and $T_{\text {sfc }}$ simulations as well as the overall model performance. The original Zilitinkevich (1995) $z_{0 h}$ scheme in the Noah LSM (N2.7) cannot reproduce these diurnal variations, which can be enhanced by modifying the empirical coefficient $C_{\text {zil }}$. Zeng et al. (2012) and Z12 suggested using a range of values around 0.9 for $C_{\mathrm{zil}}$ together with explicit consideration of the GVF (Z12). This modification performs satisfactorily over the surface covered with sparse GVF, but it is inadequate for surfaces covered with dense GVF. Alternatively, the vegetation type-dependent formulation for 
$C_{\text {zil }}$ from Chen and Zhang (2009) calculates $C_{\text {zil }}$ as a function of the canopy height or $z_{0 \mathrm{~m}}(\mathrm{~N} 3.4)$. This scheme performs consistently well for the surface with different GVF values in different seasons in this study, which has also been demonstrated with AmeriFlux data from a wide range of land covers and climate regimes (Chen and Zhang 2009).

The $z_{0 \mathrm{~h}}$ scheme of Y08 is not associated with a specific $z_{0 \mathrm{~m}}$ scheme and also performs consistently well in the aforementioned assessment under different surface conditions. Chen et al. $(2010,2011)$ have found similar results over low vegetation and bare surfaces (e.g., alpine steppe, grassland, and deserts), but they also reported on a poor performance over densely vegetated surfaces (e.g., forest and shrubland). As such, Zeng et al. (2012) argued that it is unclear how this scheme should be used over grid cells with different GVF values. Chen et al. (2011) suggested to resolve this issue via combination of the schemes for bare soils and vegetated surfaces by taking their areal fraction into consideration, such as the $k B^{-1}$ scheme implemented in the Surface Energy Balance System (SEBS; Su 2002). Recently, Chen et al. (2013) have replaced the soil part of the $k B^{-1}$ scheme in SEBS with the $z_{0 \mathrm{~h}}$ scheme of Y08. The new scheme gave better performance than the original one over the Tibetan Plateau. However, additional validation is needed over other regions before it can be applied globally.

\section{Conclusions}

In this study, we investigated the performance of various recently developed parameterizations of roughness lengths for the Noah land surface model, as well as their effectiveness in simulating the surface heat flux transfer and land surface temperature $\left(T_{\mathrm{sfc}}\right)$ in different seasons in the source region of the Yellow River (SRYR) on the Tibetan Plateau. The major findings are as follows.

1) Monthly variations of momentum roughness length $\left(z_{0 \mathrm{~m}}\right)$ are found, which can be attributed to vegetation dynamics as well as to freeze-thaw processes, and current $z_{0 \mathrm{~m}}$ schemes can reproduce the observed $z_{0 \mathrm{~m}}$ and sensible heat flux $(H)$ satisfactorily.

2) Diurnal variations of thermal roughness length $\left(z_{0 h}\right)$ are found for surfaces covered with different green vegetation fractions (GVFs) in different seasons, and Noah's original $z_{0 \mathrm{~h}}$ scheme by Zilitinkevich (1995) cannot reproduce the diurnal variations.

3) The simulation of $H$ is much more sensitive to the $z_{0 \mathrm{~h}}$ scheme than the $z_{0 \mathrm{~m}}$ scheme, and the performance of Noah's original $z_{0 \mathrm{~h}}$ scheme in reproducing the diurnal variations of observed $z_{0 \mathrm{~h}}$ and $H$ can be enhanced by modifying Zilitinkevich's empirical coefficient $\left(C_{\mathrm{zil}}\right)$. For instance, $C_{\mathrm{zil}}$ is related to the canopy height or $z_{0 \mathrm{~m}}$ by Chen and Zhang (2009), and it is calculated based on the GVF by Z12. An alternative way is to use the $z_{0 \mathrm{~h}}$ scheme by $\mathrm{Y} 08$.

4) These newly developed $z_{0 \mathrm{~h}}$ schemes all produce better agreements with the measurements than the original one, at least over the surfaces with sparse vegetation during the winter period. However, it should be noted that for the surfaces with dense vegetation during the spring and monsoon periods, not all newly developed schemes perform consistently better than the original one.

5) The Noah land surface model originally using the Zilitinkevich $z_{0 \mathrm{~h}}$ scheme significantly overestimates $H$ and LE and underestimates $T_{\text {sfc }}$ and soil temperature in deeper layers, and the biases can be improved by about $29 \%, 79 \%, 75 \%$, and $81 \%$ respectively through implementing the most promising parameterization of roughness lengths.

Although we have not resolved the energy balance closure issue of surface flux measurements in this study, it is shown that the above findings related to $k B^{-1}, H$, and soil temperature are still valid if the measured energy budget is forced to be closed with the Bowen ratio closure method. We suggest using the $z_{0 \mathrm{~h}}$ scheme proposed by Chen and Zhang (2009) for actual applications because of its consistent performance over various surface conditions and in different seasons, that is, land cover and climate regimes. Another potential way is to integrate the $z_{0 \mathrm{~h}}$ scheme by $\mathrm{Y} 08$ for bare surfaces into an existing $k B^{-1}\left[k B^{-1}=\ln \left(z_{0 \mathrm{~m}} / z_{0 \mathrm{~h}}\right)\right]$ scheme that combines the schemes for bare soils and vegetated surfaces by taking their areal fractions into consideration, such as the work by Chen et al. (2013).

Acknowledgments. This research was funded in part by the ESA-MOST Dragon I/II program (Drought Monitoring, Prediction and Adaptation under Climatic Changes project and Young Scientists Support), the European Commission CEOP-AEGIS project (Call FP7ENV-2007-1 Grant 212921; http://www.ceop-aegis.org/), and the ESA STSE WACMOS project (www.wacmos.org). Donghai Zheng is supported by Chinese Scholarship Council (CSC). The authors thank Professor Jun Wen in CAREERI/CAS for providing the field observations.

\section{APPENDIX A}

\section{Two Methods to Estimate Momentum Roughness Length}

Following the method in Y08, the logarithmic wind profile is rewritten as 


$$
\ln z_{0 \mathrm{~m}}=\ln z-\Psi_{m}(z / L)-\kappa u / u_{*},
$$

where $z_{0 \mathrm{~m}}$ is the roughness length for momentum transfer $(\mathrm{m}), z$ is the observation height $(\mathrm{m}), \Psi_{m}$ is the stability correction function for momentum transfer, $L$ is the Obukhov length $(\mathrm{m}), \kappa$ is the von Kármán constant (taken as 0.4), $u$ is the mean wind speed $\left(\mathrm{m} \mathrm{s}^{-1}\right)$, and $u_{*}$ is the friction velocity $\left(\mathrm{m} \mathrm{s}^{-1}\right)$.

Using the five-level profile and single-level EC measurements, a dataset of $\ln \left(z_{0 \mathrm{~m}}\right)$ is generated with multiple combinations of wind speed $u$ and air temperature $T_{a}$ (six level), and the optimal values of $z_{0 \mathrm{~m}}$ for each month should correspond to the peak frequency in the histogram of $\ln \left(z_{0 \mathrm{~m}}\right)$.

Following the method in Sun (1999), Eq. (A1) can be rewritten as

$$
\begin{aligned}
u(z) & =S_{u} Y_{u}(z)+I_{u}, \\
Y_{u}(z) & =\ln (z)-\Psi_{m}(z / L), \\
S_{u} & =u_{*} / \kappa,
\end{aligned}
$$

and

$$
I_{u}=-\frac{u_{*}}{\kappa} \ln \left(z_{0 \mathrm{~m}}\right) .
$$

Similarly, using both the profile and EC observations, $Y_{u}(z)$ can be estimated at the corresponding wind observation levels (six level). Applying the linear least squares regression method for the six-level $u(z)$ versus $Y_{u}(z)$, the $z_{0 \mathrm{~m}}$ can be estimated from the regression slope $S_{u}$ and the intercept $I_{u}$ [Eqs. (A4) and (A5)] as

$$
\ln \left(z_{0 \mathrm{~m}}\right)=-I_{u} / S_{u} .
$$

Using the method of $\operatorname{Sun}(1999), \ln \left(z_{0 \mathrm{~m}}\right)$ is calculated for each time interval of observations $(30 \mathrm{~min})$, and the peak frequency histogram is used to determine the optimal values of $z_{0 \mathrm{~m}}$ for each month.

\section{APPENDIX B}

\section{Noah Land Surface Model}

The information about the governing equations in the Noah LSM to simulate surface energy balance and soil thermodynamic will be introduced briefly below, while the information about water budget (e.g., runoff and soil moisture) and cold season (e.g., snow and frozen ground) simulations in the Noah LSM can be found in Schaake et al. (1996) and Koren et al. (1999).
The surface energy balance equation in Noah LSM can be written as

$$
S \downarrow-S \uparrow+\varepsilon\left(L \downarrow-\sigma T_{\mathrm{sfc}}^{4}\right)=H+\mathrm{LE}+G_{0},
$$

where $S \downarrow$ and $S^{\uparrow}$ are the downward and upward shortwave radiation $\left(\mathrm{W} \mathrm{m}^{-2}\right)$, respectively; $L \downarrow$ is the downward longwave radiation $\left(\mathrm{W} \mathrm{m}^{-2}\right) ; T_{\mathrm{sfc}}$ is the ground surface temperature $(\mathrm{K}) ; \varepsilon$ is the surface emissivity; $\sigma$ is the Stefan-Boltzmann constant (taken as $\left.5.67 \times 10^{-8} \mathrm{~W} \mathrm{~m}^{-2} \mathrm{~K}^{4}\right) ; H$ is the sensible heat flux $\left(\mathrm{W} \mathrm{m}^{-2}\right)$; LE is the latent heat flux $\left(\mathrm{W} \mathrm{m}^{-2}\right)$; and $G_{0}$ is the ground surface heat flux $\left(\mathrm{W} \mathrm{m}^{-2}\right)$.

The ground surface heat flux is calculated following Fourier's law using the temperature gradient between the surface and the midpoint of the top soil layer:

$$
G_{0}=\kappa_{\mathrm{h} 1} \frac{T_{\mathrm{sfc}}-T_{\mathrm{s} 1}}{\Delta z_{1}}
$$

where $\kappa_{\mathrm{h} 1}$ is the thermal heat conductivity of the top soil layer $\left(\mathrm{W} \mathrm{m}^{-1} \mathrm{~K}^{-1}\right), T_{\mathrm{s} 1}$ is the temperature of the top soil layer (K), and $\Delta z_{1}$ is the depth between the surface and the midpoint of the top soil layer $(\mathrm{m})$.

The transfer of heat through the soil column is governed by the thermal diffusion equation:

$$
C_{s} \frac{\partial T}{\partial t}=\frac{\partial}{\partial z}\left(k_{h} \frac{\partial T}{\partial z}\right)
$$

where $C_{s}$ is the soil thermal heat capacity $\left(\mathrm{J} \mathrm{m}^{-3} \mathrm{~K}^{-1}\right)$. The details about the parameterization of thermal heat conductivity $\left(\kappa_{h}\right)$ and thermal heat capacity $\left(C_{s}\right)$ can be found in Peters-Lidard et al. (1998) and van der Velde et al. (2009).

The layer integrated form of Eq. (B3) is solved using a Crank-Nicholson scheme. The temperature at the bottom boundary is defined as the annual mean surface air temperature, which is specified at a depth of $8 \mathrm{~m}$. The top boundary is confined by the surface temperature, which is calculated as (van der Velde et al. 2009):

$$
T_{\mathrm{sfc}}=T_{a}+\frac{S \downarrow-S \uparrow+\varepsilon L \downarrow-H-\mathrm{LE}-G_{0}}{4 T_{a}^{3}}-\frac{1}{4} \varepsilon \sigma T_{a},
$$

where $T_{a}$ is the air temperature $(\mathrm{K})$.

The potential evaporation $\left(\mathrm{LE}_{p}\right)$ is calculated diurnally using a Penman-based approach (Mahrt and Ek 1984):

$$
\mathrm{LE}_{p}=\frac{\Delta\left(R_{n}-G_{0}\right)+\rho \lambda C_{h} u\left(q_{s}-q\right)}{1+\Delta}
$$


and

$$
R_{n}=S \downarrow-S \uparrow+\varepsilon\left(L \downarrow-\sigma T_{\mathrm{sfc}}^{4}\right),
$$

where $\Delta$ is the slope of the saturated vapor pressure curve $\left(\mathrm{kPa} \mathrm{K}^{-1}\right) ; R_{n}$ is the net radiation $\left(\mathrm{W} \mathrm{m}^{-2}\right) ; \rho$ is the density of air $\left(\mathrm{kg} \mathrm{m}^{-3}\right) ; \lambda$ is the latent heat of vaporization $\left(\mathrm{J} \mathrm{kg}^{-1}\right) ; C_{h}$ is the surface exchange coefficient for heat transfer; $u$ is the mean wind speed $\left(\mathrm{m} \mathrm{s}^{-1}\right)$; and $q_{s}$ and $q$ are the saturated and actual specific humidity $\left(\mathrm{kg} \mathrm{kg}^{-1}\right)$, respectively. Simulation of the LE is performed by applying a Jarvis-type surface resistance scheme to impose soil and atmosphere constraints to $\mathrm{LE}_{p}$, and the details can be found in Chen et al. (1996).

\section{REFERENCES}

Bastiaanssen, W. G. M., M. Menenti, R. A. Feddes, and A. A. M. Holtslag, 1998: A remote sensing surface energy balance algorithm for land (SEBAL). 1. Formulation. J. Hydrol., 212213, 198-212, doi:10.1016/S0022-1694(98)00253-4.

Brutsaert, W. H., 1982: Evaporation into the Atmosphere: Theory, History and Applications. Springer, $316 \mathrm{pp}$.

_ 1998: Land-surface water vapor and sensible heat flux: Spatial variability, homogeneity, and measurement scales. Water Resour. Res., 34, 2433-2442, doi:10.1029/98WR01340.

Chen, F., and Y. Zhang, 2009: On the coupling strength between the land surface and the atmosphere: From viewpoint of surface exchange coefficients. Geophys. Res. Lett., 36, L10404, doi:10.1029/2009GL037980.

, and Coauthors, 1996: Modeling of land surface evaporation by four schemes and comparison with FIFE observations. J. Geophys. Res., 101, 7251-7268, doi:10.1029/95JD02165.

_ Z Z. Janjić, and K. Mitchell, 1997: Impact of atmospheric surfacelayer parameterizations in the new land-surface scheme of the NCEP mesoscale Eta model. Bound.-Layer Meteor., 85, 391421, doi:10.1023/A:1000531001463.

Chen, X., Z. Su, Y. Ma, K. Yang, J. Wen, and Y. Zhang, 2013: An improvement of roughness height parameterization of Surface Energy Balance System (SEBS) over the Tibetan Plateau. J. Appl. Meteor. Climatol., 52, 607-622, doi:10.1175/ JAMC-D-12-056.1.

Chen, Y., K. Yang, D. Zhou, J. Qin, and X. Guo, 2010: Improving the Noah land surface model in arid regions with an appropriate parameterization of the thermal roughness length. J. Hydrometeor., 11, 995-1006, doi:10.1175/2010JHM1185.1.

,-- J J. He, J. Qin, J. Shi, J. Du, and Q. He, 2011: Improving land surface temperature modeling for dry land of China. J. Geophys. Res., 116, D20104, doi:10.1029/2011JD015921.

Dente, L., Z. Vekerdy, J. Wen, and Z. Su, 2012: Maqu network for validation of satellite-derived soil moisture products. Int. J. Appl. Earth Obs. Geoinf., 17, 55-65, doi:10.1016/j.jag.2011.11.004.

Ek, M. B., K. E. Mitchell, Y. Lin, E. Rogers, P. Grunmann, V. Koren, G. Gayno, and J. D. Tarpley, 2003: Implementation of Noah land surface model advances in the National Centers for Environmental Prediction operational mesoscale Eta model. J. Geophys. Res., 108, 8851, doi:10.1029/2002JD003296.

Foken, T., 2008: The energy balance closure problem: An overview. Ecol. Appl., 18, 1351-1367, doi:10.1890/06-0922.1.

Garratt, J. R., 1994: The Atmospheric Boundary Layer. Cambridge University Press, $336 \mathrm{pp}$
Gutman, G., and A. Ignatov, 1998: The derivation of the green vegetation fraction from NOAA/AVHRR data for use in numerical weather prediction models. Int. J. Remote Sens., 19, 1533-1543, doi:10.1080/014311698215333.

Hong, S., V. Lakshmi, E. E. Small, F. Chen, M. Tewari, and K. W. Manning, 2009: Effects of vegetation and soil moisture on the simulated land surface processes from the coupled WRF/ Noah model. J. Geophys. Res., 114, D18118, doi:10.1029/ 2008JD011249.

Jiang, X., G.-Y. Niu, and Z.-L. Yang, 2009: Impacts of vegetation and groundwater dynamics on warm season precipitation over the central United States. J. Geophys. Res., 114, D06109, doi:10.1029/2008JD010756.

Kohsiek, W., C. Liebethal, T. Foken, R. Vogt, S. Oncley, Ch. Bernhofer, and H. Debruin, 2007: The Energy Balance Experiment EBEX-2000. Part III: Behaviour and quality of the radiation measurements. Bound.-Layer Meteor., 123, 5575, doi:10.1007/s10546-006-9135-8.

Koike, T., 2004: The Coordinated Enhanced Observing Period: An initial step for integrated global water cycle observation. WMO Bull., 53, 115-121.

Koren, V., J. Schaake, K. Mitchell, Q. Y. Duan, F. Chen, and J. M. Baker, 1999: A parameterization of snowpack and frozen ground intended for NCEP weather and climate models. J. Geophys. Res., 104, 19569-19585, doi:10.1029/1999JD900232.

Li, S., S. Lü, Y. Ao, and L. Shang, 2009: Annual variations in the surface radiation budget and soil water and heat content in the upper Yellow River area. Environ. Geol., 57, 389-395, doi:10.1007/s00254-008-1308-y.

Ma, Y., O. Tsukamoto, J. Wang, H. Ishikawa, and I. Tamagawa, 2002: Analysis of aerodynamic and thermodynamic parameters on the grassy marshland surface of Tibetan Plateau. Prog. Nat. Sci., 12, 36-40.

— S. Kang, L. Zhu, B. Xu, L. Tian, and T. Yao, 2008a: Tibetan observation and research platform: Atmosphere-land interaction over a heterogeneous landscape. Bull. Amer. Meteor. Soc., 89, 1487-1492, doi:10.1175/2008BAMS2545.1.

_ M. Menenti, R. Feddes, and J. Wang, 2008b: Analysis of the land surface heterogeneity and its impact on atmospheric variables and the aerodynamic and thermodynamic roughness lengths. J. Geophys. Res., 113, D08113, doi:10.1029/ 2007JD009124.

Mahrt, L., and M. Ek, 1984: The influence of atmospheric stability on potential evaporation. J. Climate Appl. Meteor., 23, 222234, doi:10.1175/1520-0450(1984)023<0222:TIOASO > 2.0.CO;2. _, and H. Pan, 1984: A two-layer model of soil hydrology. Bound.-Layer Meteor., 29, 1-20, doi:10.1007/BF00119116.

Martano, P., 2000: Estimation of surface roughness length and displacement height from single-level sonic anemometer data. J. Appl. Meteor., 39, 708-715, doi:10.1175/ 1520-0450(2000)039<0708:EOSRLA > 2.0.CO;2.

Massman, W. J., and X. Lee, 2002: Eddy covariance flux corrections and uncertainties in long-term studies of carbon and energy exchanges. Agric. For. Meteor., 113, 121-144, doi:10.1016/ S0168-1923(02)00105-3.

Niu, G.-Y., and Coauthors, 2011: The community Noah land surface model with multiparameterization options (Noah-MP): 1. Model description and evaluation with local-scale measurements. J. Geophys. Res., 116, D12109, doi:10.1029/ 2010JD015139.

Pan, H. L., and L. Mahrt, 1987: Interaction between soil hydrology and boundary-layer development. Bound.-Layer Meteor., 38, 185-202, doi:10.1007/BF00121563. 
Peters-Lidard, C. D., E. Blackburn, X. Liang, and E. F. Wood, 1998: The effect of soil thermal conductivity parameterization on surface energy fluxes and temperatures. J. Atmos. Sci., 55, 1209-1224, doi:10.1175/1520-0469(1998)055<1209:TEOSTC $>2.0 . C O ; 2$.

Philipona, and Coauthors, 2001: Atmospheric longwave irradiance uncertainty: Pyrgeometers compared to an absolute skyscanning radiometer, atmospheric emitted radiance interferometer, and radiative transfer model calculations. J. Geophys. Res., 106, 28129-28141, doi:10.1029/2000JD000196.

Qin, J., K. Yang, S. Liang, and X. Guo, 2009: The altitudinal dependence of recent rapid warming over the Tibetan Plateau. Climatic Change, 97, 321-327, doi:10.1007/s10584-009-9733-9.

Schaake, J., V. Koren, and Q. Y. Duan, 1996: Simple water balance model for estimating runoff at different spatial and temporal scales. J. Geophys. Res., 101, 7461-7475, doi:10.1029/ 95JD02892.

Schaudt, K. J., 1998: A new method for estimating roughness parameters and evaluating the quality of observations. J. Appl. Meteor., 37, 470-476, doi:10.1175/1520-0450(1998)037<0470: ANMFER $>2.0 . \mathrm{CO} ; 2$

Su, Z., 2002: The surface energy balance system (SEBS) for estimation of turbulent heat fluxes. Hydrol. Earth Syst. Sci., 6, 8599, doi:10.5194/hess-6-85-2002.

—, T. Schmugge, W. P. Kustas, and W. J. Massman, 2001: An evaluation of two models for estimation of the roughness height for heat transfer between the land surface and the atmosphere. J. Appl. Meteor., 40, 1933-1951, doi:10.1175/15200450(2001)040<1933:AEOTMF>2.0.CO;2.

— , and Coauthors, 2011: The Tibetan Plateau observatory of plateau scale soil moisture and soil temperature (Tibet-Obs) for quantifying uncertainties in coarse resolution satellite and model products. Hydrol. Earth Syst. Sci., 15, 2303-2316, doi:10.5194/hess-15-2303-2011.

Sun, J., 1999: Diurnal variations of thermal roughness height over a grassland. Bound.-Layer Meteor., 92, 407-427, doi:10.1023/ A:1002071421362.

Tanaka, K., I. Tamagawa, H. Ishikawa, Y. Ma, and Z. Hu, 2003: Surface energy budget and closure of the eastern Tibetan Plateau during the GAME-Tibet IOP 1998. J. Hydrol., 283, 169-183, doi:10.1016/S0022-1694(03)00243-9.

Twine, T. E., and Coauthors, 2000: Correcting eddy-covariance flux underestimates over a grassland. Agric. For. Meteor., 103, 279 300, doi:10.1016/S0168-1923(00)00123-4.

van den Hurk, B. J. J. M., and A. A. M. Holtslag, 1997: On the bulk parameterization of surface fluxes for various conditions and parameter ranges. Bound.-Layer Meteor., 82, 119-133, doi:10.1023/A:1000245600901.

van der Velde, R., Z. Su, M. Ek, M. Rodell, and Y. Ma, 2009: Influence of thermodynamic soil and vegetation parameterizations on the simulation of soil temperature states and surface fluxes by the Noah LSM over a Tibetan plateau site. Hydrol. Earth Syst. Sci., 13, 759-777, doi:10.5194/hess-13-759-2009.

Verhoef, A., H. A. R. DeBruin, and B. J. J. M. van den Hurk, 1997: Some practical notes on the parameter $\mathrm{kB}^{-1}$ for sparse canopies. J. Appl. Meteor., 36, 560-572, doi:10.1175/ 1520-0450(1997)036<0560:SPNOTP $>2.0$.CO;2.

Wang, B., Q. Bao, B. Hoskins, G. Wu, and Y. Liu, 2008: Tibetan Plateau warming and precipitation changes in East Asia. Geophys. Res. Lett., 35, L14702, doi:10.1029/2008GL034330.

Wang, G. X., X. Y. Guo, Y. P. Shen, and G. D. Cheng, 2003: Evolving landscapes in the headwaters area of the Yellow River (China) and their ecological implications. Landscape Ecol., 18, 363-375, doi:10.1023/A:1026187826596.
Wang, S., and Y. Ma, 2011: Characteristics of land-atmosphere interaction parameters over the Tibetan Plateau. J. Hydrometeor., 12, 702-708, doi:10.1175/2010JHM1275.1.

Wang, S. Y., Y. Zhang, S. Lv, H. Liu, and L. Shang, 2013: Estimation of turbulent fluxes using the flux-variance method over an alpine meadow surface in eastern Tibetan Plateau. $A d v$. Atmos. Sci., 30, 411-424, doi:10.1007/s00376-012-2056-1.

Wiernga, J., 1993: Representative roughness parameters for homogeneous terrain. Bound.-Layer Meteor., 63, 323-363, doi:10.1007/BF00705357.

Wilson, K., and Coauthors, 2002: Energy balance closure at FLUXNET sites. Agric. For. Meteor., 113, 223-243, doi:10.1016/ S0168-1923(02)00109-0.

Wu, T., L. Zhao, R. Li, Q. Wang, C. Xie, and Q. Pang, 2012: Recent ground surface warming and its effects on permafrost on the central Qinghai-Tibet Plateau. Int. J. Climatol., 33, 920-930, doi: $10.1002 /$ joc. 3479 .

$\mathrm{Xu}, \mathrm{X}$., and Coauthors, 2008: A new integrated observational system over the Tibetan Plateau. Bull. Amer. Meteor. Soc., 89, 1492-1496, doi:10.1175/2008BAMS2557.1.

Yang, J., Y. Ding, and R. Chen, 2007: Climatic causes of ecological and environmental variations in the source regions of the Yangtze and Yellow Rivers of China. Environ. Geol., 53,113121, doi:10.1007/s00254-006-0623-4.

Yang, K., T. Koike, and D. Yang, 2003: Surface flux parameterization in the Tibetan Plateau. Bound.-Layer Meteor., 106, 245-262, doi:10.1023/A:1021152407334.

,,-- H. Ishikawa, and Y. Ma, 2004: Analysis of the surface energy budget at a site of GAME/Tibet using a single-source model. J. Meteor. Soc. Japan, 82, 131-153, doi:10.2151/jmsj.82.131.

— surfaces: Characteristics and parameterization. J. Appl. Meteor. Climatol., 47, 276-290, doi:10.1175/2007JAMC1547.1.

— - X. Guo, J. He, J. Qin, and T. Koike, 2011a: On the climatology and trend of the atmospheric heat source over the Tibetan Plateau: An experiments-supported revisit. J. Climate, 24, 1525-1541, doi:10.1175/2010JCLI3848.1.

, B. Ye, D. Zhou, B. Wu, T. Foken, J. Qin, and Z. Zhou, 2011b: Response of hydrological cycle to recent climate changes in the Tibetan Plateau. Climatic Change, 109, 517-534, doi:10.1007/ s10584-011-0099-4.

Zeng, X., Z. Wang, and A. Wang, 2012: Surface skin temperature and the interplay between sensible and ground heat fluxes over arid regions. J. Hydrometeor., 13, 1359-1370, doi:10.1175/ JHM-D-11-0117.1.

Zhao, L., C.-L. Ping, D. Yang, G. Cheng, Y. Ding, and S. Liu, 2004: Changes of climate and seasonally frozen ground over the past 30 years in Qinghai-Xizang (Tibetan) Plateau, China. Global Planet. Change, 43, 19-31, doi:10.1016/j.gloplacha.2004.02.003.

Zheng, W., H. Wei, Z. Wang, X. Zeng, J. Meng, M. Ek, K. Mitchell, and J. Derber, 2012: Improvement of daytime land surface skin temperature over arid regions in the NCEP GFS model and its impact on satellite data assimilation. J. Geophys. Res., 117, D06117, doi:10.1029/2011JD015901.

Zhou, D., and R. Huang, 2012: Response of water budget to recent climatic changes in the source region of the Yellow River. Chin. Sci. Bull., 57, 2155-2162, doi:10.1007/ s11434-012-5041-2.

Zilitinkevich, S. S., 1995: Non-local turbulent transport: Pollution dispersion aspects of coherent structure of convective flows. Air Pollution Theory and Simulation, H. Power, N. Moussiopoulos, and C. A. Brebbia, Eds., Vol. I, Air Pollution III, Computational Mechanics Publications, 53-60. 